\title{
MODELING THE SUSTAINABILITY OF WALLEYE POPULATIONS IN NORTHERN WISCONSIN LAKES
}

\author{
by \\ Amy M. Schueller \\ A Thesis \\ Submitted as partial fulfillment of the \\ Requirements of the degree \\ MASTER OF SCIENCE \\ IN \\ NATURAL RESOURCES (FISHERIES) \\ College of Natural Resources \\ UNIVERSITY OF WISCONSIN \\ Stevens Point, Wisconsin
}

August 2005 


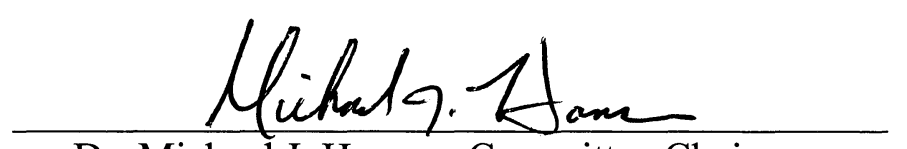

Dr. Michael J. Hansen, Committee Chairman

Professor of Fisheries

College of Natural Resources

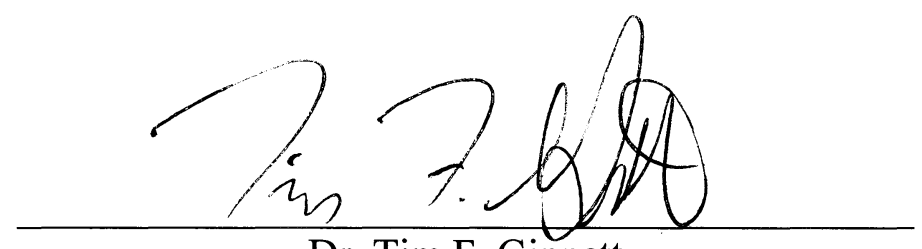

Dr. Tim F. Ginnett

Assistant Professor of Wildlife Ecology

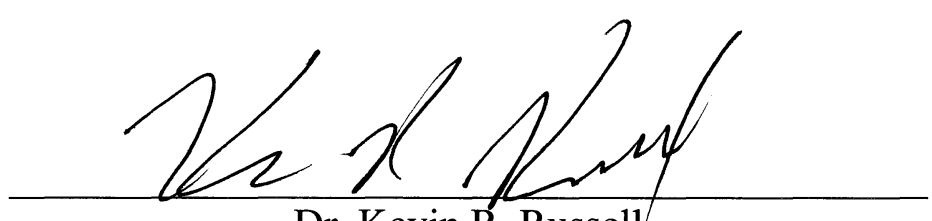

Dr. Kevin R. Russell

Assistant Professor of Wildlife Ecology and Management

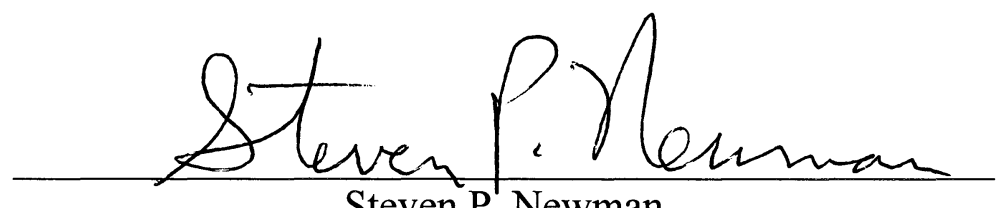

Steven P. Newman

Wisconsin Department of Natural Resources 


\section{ABSTRACT}

Walleye populations in northern Wisconsin face exploitation from angling and spearing fisheries that are regulated using a total annual exploitation rate of $35 \%$. However, the sustainability of the $35 \%$ exploitation rate has never been evaluated, so my primary objective was to evaluate the sustainability of walleye populations across a range of lake sizes (abundance varies with lake size) that are then subjected to ranges of exploitation rates and allocations of angling and spearing harvest (the fisheries differ greatly in size selectivity). I also sought to determine if age at maturity and lengthspecific fecundity were density dependent for walleyes in Big Crooked Lake, Wisconsin, during 1997-2003, where walleye were purposely subjected to high exploitation as part of a field evaluation of walleye population sustainability under exploitation stress. I completed my secondary objective first to incorporate the results into my primary objective.

To complete my secondary objective, I evaluated the effect of adult walleye Sander vitreus population density on age at $50 \%$ maturity and length-specific fecundity in Big Crooked Lake, Wisconsin, during 1997-2003. Abundance of adult walleye from mark-recapture surveys ranged from 2,046 fish ( 3 walleye/acre) to 4,901 fish ( 7 walleye/acre). Age at $50 \%$ maturity ranged from 3.89 years to 4.88 years, length of walleye sampled for fecundity ranged from 13.0 in to 24.7 in, and average fecundity of a 17-in walleye ranged from 41,061 eggs to 53,009 eggs. Age at 50\% maturity increased significantly as adult walleye population density increased, whereas average fecundity of a 17 -in walleye did not change significantly with density. Therefore, age at $50 \%$ maturity 
could be used as an indicator of population density and exploitation stress and thus could be used to set desired levels of harvest.

To complete my primary objective, I developed an age-structured population model for estimating extinction risk and time to extinction for a hypothetical walleye population at a specified exploitation rate, fishery allocation, and initial abundance. The age-structured population model was parameterized from intensive surveys of walleye populations in Escanaba Lake and extensive surveys of walleye populations in northern Wisconsin lakes. Simulations covered a range of annual exploitation rates that included the currently-accepted rate of $35 \%$ and a range of population sizes that are presently included in regression models that relate walleye abundance to lake surface area. The risk of extinction began to increase above zero at an exploitation rate of $56-61 \%$ for an unregulated angling fishery, $73-76 \%$ for an angling fishery with a 15 in minimum length limit, and $75-80 \%$ for a spearing fishery. The probability of decline began to increase above zero at an exploitation rate of $47 \%$ for an unregulated angling fishery, $60 \%$ for an angling fishery with a 15 in minimum length limit, and $60 \%$ for a spearing fishery. As the exploitation rate increased, the average adult abundance decreased and the time to extinction decreased for all lake sizes and initial population sizes. I conclude that the current maximum exploitation rate of $35 \%$ is sustainable for all lake sizes and initial population sizes and that angler daily bag limits and spearing quotas could be increased while still ensuring the sustainability of walleye populations. However, steps should be taken to implement a field experiment to verify the results of the simulation model before the results are used for management. 


\section{ACKNOWLEDGMENTS}

Funding for this study was provided by the Wisconsin Department of Natural Resources and by the U. S. Forest Service, Federal Aid in Sport Fish Restoration (grant F-95-P). I would like to thank personnel at the Escanaba Lake Research Station for collection of data and Dairymen's Incorporated for assisting in data collection and performing the creel census on Big Crooked Lake. I would also like to thank the Portage County Wildlife Club for additional funding support in the form of scholarship funding.

I would like to thank my advisor Dr. Michael J. Hansen for being my guide through graduate school and for helping me to see the dynamic world of fisheries. He has been a great mentor throughout the entire process, and I am eternally indebted to him. I could not have asked for better guidance for my career. I would also like to thank him for helping me to become a better more succinct writer, and for helping me through the peer review process so that my first manuscript could be published with my co-authors Mike Hansen, Steve Newman, and Clay Edwards.

I would like to thank my graduate committee: Dr. Michael Hansen, Dr. Tim

Ginnett, Dr. Kevin Russell, and Steve Newman for taking time out of their busy schedules to have meetings to discuss my proposal and other aspects of my education and thesis. I would also like to thank them for asking difficult questions, which always helped me to ask more questions and helped me to look at every situation in its entirety.

I would like to thank my family for always supporting me in every endeavor. I would especially like to thank my husband Ray for allowing me to follow my dreams, for quitting his job to move here with me, and for always being around for emotional support. I enjoyed completing this journey with you by my side. 
I would also like to thank all of my colleagues: Paul Bergman, Lisa Corradin, Jon Deroba, Jen Hurt, Julie Nieland, Casey Schoenebeck, and Jordan Weeks. You have all taught me so much. I will never forget our dance moves, card games, monopoly and trivial pursuit games, camping and fishing trips, or the days we spent together in the office trying to figure out some complicated fisheries model or mathematical equation. I wish you all the best that life has to offer. 


\section{TABLE OF CONTENTS}

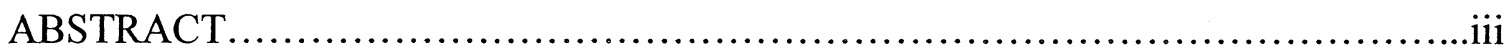

ACKNOWLEDGMENTS...........................................................

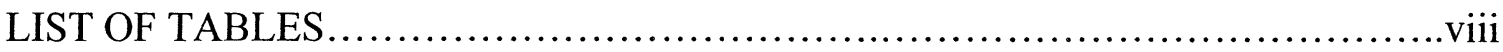

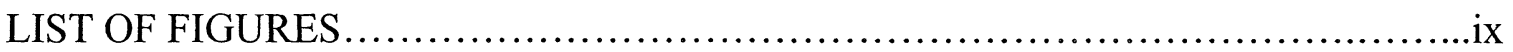

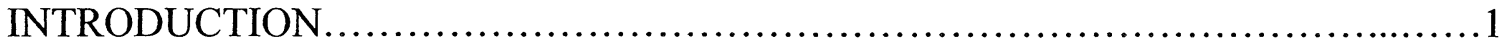

CHAPTER I: DENSITY DEPENDENCE OF WALLEYE MATURITY AND

FECUNDITY IN BIG CROOKED LAKE, WISCONSIN, 1997-2003

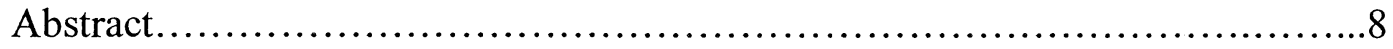

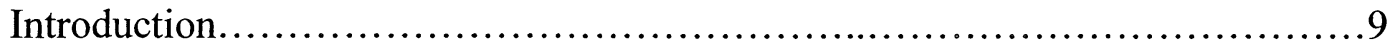

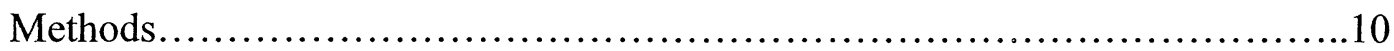

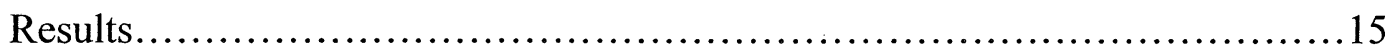

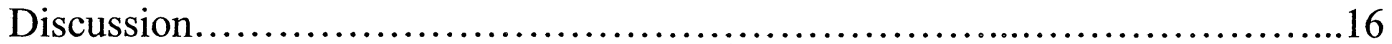

CHAPTER II: SIMULATING THE SUSTAINABILITY OF WALLEYE POPULATIONS IN NORTHERN WISCONSIN LAKES

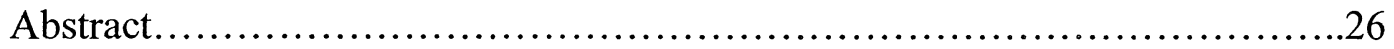

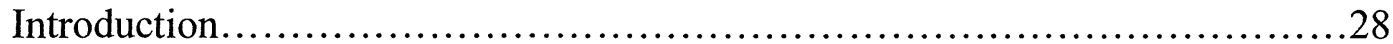

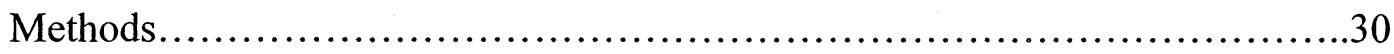

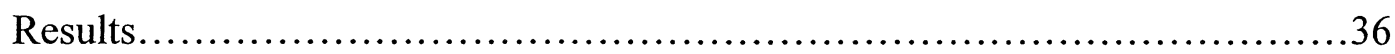

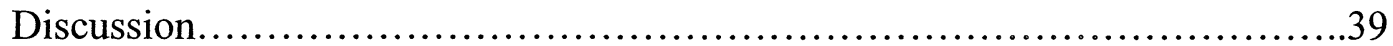

Management Implications................................................41

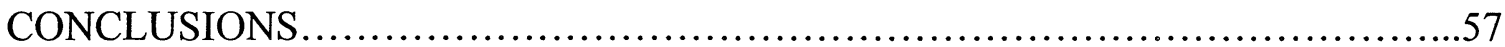

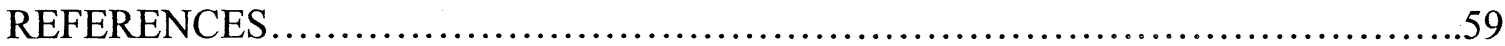




\section{LIST OF TABLES}

1. The parameters that were tested for the sensitivity analysis and the parameter descriptions for each of the parameters

2. Parameter tested, deviation tested, mean average adult abundance, the upper and lower $95 \%$ of the average adult abundance, and the percent difference between the baseline mean and the mean for each parameter deviation for an angling only fishery where the model was run 1000 simulations for 200 years.................44

3. Parameter tested, deviation tested, mean average adult abundance, the upper and lower $95 \%$ of the average adult abundance, and the percent difference between the baseline mean and the mean for each parameter deviation for a spearing only fishery where the model was run 1000 simulations and 200 years...............45 


\section{LIST OF FIGURES}

1. The ceded territory of northern Wisconsin, which is denoted by the line and includes pieces of 30 counties and 22,400 square miles........................

2. Adult abundance (upper panel), age at $50 \%$ maturity (middle panel), and fecundity (lower panel) during 1997-2003 ( \pm 95\% confidence interval) of walleye in Big Crooked Lake, Wisconsin. Numbers above abundance estimates are numbers of recaptures in each year, numbers above age at $50 \%$ maturity are numbers of fish for each year, and numbers below age at 50\% maturity and above fecundity estimates are sample sizes in each year...........................20

3. Age at $50 \%$ maturity versus adult population density (upper panel) and age at $50 \%$ maturity versus adult population density in the previous year (lower panel) for walleye in Big Crooked Lake, Wisconsin, during 1997-2003

4. Observed (error bars $= \pm 95 \%$ confidence interval) and predicted adult walleye population density (regression line $\pm 95 \%$ prediction interval) versus age at $50 \%$ maturity for walleye in Big Crooked Lake, Wisconsin during 1997-2003........22

5. Mean length at age 3 versus adult population density (upper panel) and mean length at age 3 versus adult population density in the previous year (lower panel) for walleye in Big Crooked Lake, Wisconsin, during 1997-2003................23

6. Age at $50 \%$ maturity versus mean length at age 3 for walleye in Big Crooked

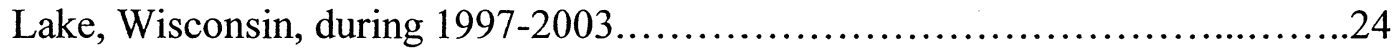

7. Mean fecundity of a 17-in walleye versus adult population density (upper panel) and mean fecundity of a 17 -in walleye versus adult population density in the previous year (lower panel) for walleye in Big Crooked Lake, Wisconsin, during 1997-2003.

8. A schematic diagram of the simulation model where $i$ is year and $j$ is age and the inputs are the total instantaneous fishing mortality rate $\left(F_{i}\right)$ for each fishery in year $i$ and the initial abundance $\left(N_{i j}\right)$ in year $i$ for age $j \ldots \ldots \ldots \ldots \ldots \ldots \ldots \ldots \ldots . \ldots \ldots$

9. Selectivity curves for an unregulated angling fishery (upper panel), an angling fishery with a 15 in minimum length limit (middle panel), and a spearing fishery (lower panel) in Wisconsin's ceded territory................................47

10. The probability of extinction versus exploitation rate for initial population sizes of 128 adult walleyes in a 100 -acre lake, 592 adult walleyes in a 500 -acre lake, 1,139 adult walleyès in a 1,000-acre lake, 5,158 adult walleyes in a 5,000-acre lake, and 9,844 adult walleyes in a 10,000-acre lake with unregulated angling exploitation (upper panel), angling exploitation with a 15 in minimum length limit 
(middle panel), and spearing exploitation (lower panel). Simulations were run 1,000 times for 200 years.

11. The probability of decline versus exploitation rate for initial population sizes of 128 adult walleyes in a 100 -acre lake, 592 adult walleyes in a 500 -acre lake, 1,139 adult walleyes in a 1,000-acre lake, 5,158 adult walleyes in a 5,000-acre lake, and 9,844 adult walleyes in a 10,000-acre lake with unregulated angling exploitation (upper panel), angling exploitation with a 15 in minimum length limit (middle panel), and spearing exploitation (lower panel). Simulations were run 1,000 times for 200 years.

12. The average adult abundance $\pm 95 \%$ confidence intervals versus exploitation rate for initial population sizes of 128 adult walleyes in a 100-acre lake (panel a), 592 adult walleyes in a 500-acre lake (panel b), 1,139 adult walleyes in a 1,000-acre lake (panel c), 5,158 adult walleyes in a 5,000-acre lake (panel d), and 9,844 adult walleyes in a 10,000-acre lake (panel e) with unregulated angling exploitation. Simulations were run 1,000 times for 200 years. The horizontal line represents the initial population size.

13. The time to extinction $\pm 95 \%$ confidence intervals versus angling exploitation rate for initial population sizes of 128 adult walleyes in a 100-acre lake (panel a), 592 adult walleyes in a 500-acre lake (panel b), 1,139 adult walleyes in a 1,000-acre lake (panel c), 5,158 adult walleyes in a 5,000-acre lake (panel d), and 9,844 adult walleyes in a 10,000-acre lake (panel e) with unregulated angling exploitation. Simulations were run 1,000 times for 200 years

14. Initial population size versus time to extinction $\pm 95 \%$ confidence intervals for a constant exploitation rate for the unregulated angling fishery (upper panel), the angling fishery with a 15 in minimum length limit (middle panel), and the spearing fishery (lower panel). Simulations were run 1,000 times for 200 years

15. The average adult abundance $\pm 95 \%$ confidence intervals versus exploitation rate for initial population sizes of 128 adult walleyes in a 100-acre lake (panel a), 592 adult walleyes in a 500-acre lake (panel b), 1,139 adult walleyes in a 1,000-acre lake (panel c), 5,158 adult walleyes in a 5,000-acre lake (panel d), and 9,844 adult walleyes in a 10,000-acre lake (panel e) with angling exploitation with a 15 in minimum length limit. Simulations were run 1,000 times for 200 years. The horizontal line represents the initial population size

16. The time to extinction $\pm 95 \%$ confidence intervals versus exploitation rate for initial population sizes of 128 adult walleyes in a 100-acre lake (panel a), 592 adult walleyes in a 500-acre lake (panel b), 1,139 adult walleyes in a 1,000-acre lake (panel c), 5,158 adult walleyes in a 5,000-acre lake (panel d), and 9,844 adult walleyes in a 10,000-acre lake (panel e) with angling exploitation with a 15 in minimum length limit. Simulations were run 1,000 times for 200 years.........54 
17. The average adult abundance $\pm 95 \%$ confidence intervals versus exploitation rate for initial population sizes of 128 adult walleyes in a 100-acre lake (panel a), 592 adult walleyes in a 500-acre lake (panel b), 1,139 adult walleyes in a 1,000-acre lake (panel c), 5,158 adult walleyes in a 5,000-acre lake (panel d), and 9,844 adult walleyes in a 10,000-acre lake (panel e) with spearing exploitation. Simulations were run 1,000 times for 200 years. The horizontal line represents the initial population size.

18. The time to extinction $\pm 95 \%$ confidence intervals versus exploitation rate for initial population sizes of 128 adult walleyes in a 100-acre lake (panel a), 592 adult walleyes in a 500-acre lake (panel b), 1,139 adult walleyes in a 1,000-acre lake (panel c), 5,158 adult walleyes in a 5,000-acre lake (panel d), and 9,844 adult walleyes in a 10,000-acre lake (panel e) with spearing exploitation. Simulations

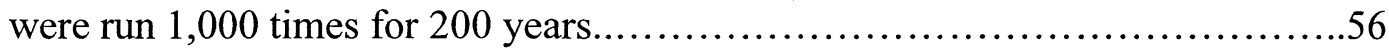




\section{INTRODUCTION}

Walleyes Sander vitreus are an ecologically important top predator in many coolwater aquatic ecosystems (Ryder and Kerr 1990). Walleyes spawn in spring from mid-April to early May, generally after ice out, when the water temperature is $42-50{ }^{\circ} \mathrm{F}$ (Becker 1983). Walleyes generally prefer a rocky substrate for spawning. Egg hatch time is directly related to water temperature. Walleyes generally stay in deeper water during the day and move to shallower water at night to feed. Walleyes tend to consume all species of fish and large invertebrates, so their diet consists primarily of what is most abundant at the time. In many waters, walleyes coexist with yellow perch in a close predator-prey relationship. On average, females reach a larger maximum size ( $\sim 30 \mathrm{in})$ than males ( 20 in). The average life span of a walleye is about 7 years, but walleyes may live 18 to 20 years.

According to the National Survey of Fishing, Hunting, and Wildlife-Associated Recreation, 28.4 million anglers participated in freshwater fishing in the U. S. in 2001 (USFWS 2003). Freshwater anglers, who make up $82 \%$ of anglers in the U. S., spent 467 million days fishing and over $\$ 21.3$ billion on fishing trips and equipment. Walleye were commonly sought in the U. S. by anglers. In 2001, 1.8 million anglers fished in the Great Lakes, and walleyes were the third most popular fish. About 1.4 million anglers fished in Wisconsin in 2001, and anglers spent $\$ 1$ billion in fishing-related expenses (USFWS 2003). In Wisconsin, walleyes are the most highly sought sport and food fish (McClanahan 2003).

In Wisconsin, the center of the walleye's range lies on the ceded territory, the northern one-third of the state that includes pieces of 30 counties and 22,400 square miles 
(Figure 1; BIA 1991; BIA 2003). Of 14,563 lakes in Wisconsin, $77 \%$ are in the ceded territory (Staggs et al. 1990). Of those lakes, 919 contain walleye and vary in size from 22 to 15,300 acres. Walleye lakes are classified by the type of recruitment that sustains the walleye population (natural reproduction, stocking, or a combination of the two).

The ceded territory of northern Wisconsin was defined by the 1837 and 1842 treaties with the Lake Superior Chippewa tribes (Staggs et al. 1990). In these treaties, the Lake Superior Chippewa tribes reserved their right to live on the land and harvest from the land. In 1850, the president of the United States, Zachary Taylor, ordered the tribes of the ceded territory onto reservations, and in 1854 , permanent reservations were established for the Lake Superior Chippewa tribes. The tribes were allowed to harvest natural resources found within their permanent reservations. After a series of Federal court cases from 1973 to 1990 , the Court affirmed and clarified the rights of the Lake Superior Chippewa tribes to hunt, fish, and gather off reservation (BIA 1991; BIA 2003). The first tribal spearing season occurred in 1985 , and spearing is the number one tribal harvest method for fish.

The Wisconsin Department of Natural Resources (WDNR) and the Great Lakes Indian Fish and Wildlife Commission (GLIFWC) jointly manage the walleye fishery of the ceded territory for a sustainable future. A maximum exploitation rate of $35 \%$ was agreed upon by state and tribal biologists as sustainable based on past data (BIA 1991). Each year, by 15 March, the Chippewa tribes notify the Wisconsin Department of Natural Resources which lakes they intend to harvest and how many fish they intend to harvest from each lake during the upcoming harvest season (Staggs et al. 1990). The number of fish that can be harvested is a quota based on estimates of abundance and the $35 \%$ 
exploitation rate. If past estimates of abundance are available, quotas include safety factors to account for temporal changes in abundance from the time when the abundance was estimated to the time when the estimate is used (Hansen et al. 1991). Adult walleye abundance increases as a function of lake size and is used to set harvest limits when no current data are available (Hansen 1989; Staggs et al. 1990; Nate et al. 2000). After spearing quotas are declared, the Wisconsin Department of Natural Resources alters angler bag limits to account for tribal harvest. Tribal and state harvest is regulated so as to not exceed the $35 \%$ exploitation rate more than 1 in 40 times, which means that $2.5 \%$ of the walleye populations in the ceded territory are at risk of overexploitation (Hansen et al. 1991).

Angling and spearing fisheries differ in level of participation, selectivity, harvest, and monitoring. The angling fishery in the ceded territory affects all 919 walleye lakes, whereas the spearing fishery affects only 101-171 lakes per year (BIA 2003). Anglerharvested walleyes average about 14 inches, while spearing-harvested walleyes average about 16 inches (BIA 1991). The angling fishery harvests both juvenile and mature walleyes, while the spearing fishery harvests only mature walleyes. The average annual exploitation rate for an individual lake was $8.38 \%$ for angling and $3.45 \%$ for spearing (Beard et al. 2003b). Catchability, or the proportion of the abundance removed per unit of effort, was 0.032 per hour for the angling fishery and 6.579 per hour for the spearing fishery, which means that spearing is more than 200 times more efficient than angling (Hansen et al. 2005). Angler harvest is estimated using creel surveys where a number of random lakes each year are surveyed during random times. Tribal spearers are required to show their catch to a tribal creel clerk and warden so that their entire catch can be 
measured and counted to prevent exceeding harvest quotas. Angling occurs from the first Saturday in May to the first of March the following year, while spearing occurs for a few weeks in spring while sexually mature walleyes are attempting to spawn.

Concerns about the sustainability of angling and spearing fisheries have arisen since the start of the off reservation harvest in 1985 (Staggs et al. 1990). Anglers are concerned that spearing of spawning walleyes and harvest of large females may jeopardize future populations (Staggs et al. 1990). However, mature females do not stay on spawning grounds long, so are not as vulnerable to spearing harvest as mature males. Most walleyes (84\%) speared during 1990-2001 were males (BIA 2003). Some biologists are concerned because spearing is more efficient than angling, so the level of harvest can remain high even when population density is low, which could potentially drive a population into collapse (Hansen et al. 2005).

The 35\% exploitation rate has never been evaluated for sustainability, so I built an age-structured population model to determine if the $35 \%$ exploitation rate is sustainable. I also determined which exploitation rates are sustainable with varying levels of initial abundance. Many dynamic rates play a role in the sustainability of a population and therefore must be taken into account when evaluating sustainability. Some of these dynamic rates include mortality (natural and fishing), recruitment, fecundity, age at maturity, and growth. These dynamic rates are often affected by factors such as population abundance, population growth rate, and environmental stochasticity. Submodels for each dynamic rate will be included in the age-structured population model. Sub-models for fecundity and age at maturity will be derived in this study, whereas others will be taken from the literature. 
Sustainable exploitation rates may vary from lake to lake due to the many factors that predispose a population to an increased extinction risk. Extinction risk is often used as a criterion for sustainable biological resources (Hakoyama and Iwasa 2000). Factors that predispose a population to an increased risk of extinction include a small initial population size, a low intrinsic rate of increase, environmental stochasticity, demographic stochasticity, and species specialists (Ricklefs 1983; Pimm et al. 1988; Tracy and George 1992). Having different exploitation rates for various lake sizes may be necessary to reduce extinction risk because small lakes with small initial population sizes would require a lower exploitation rate compared to large lakes with large initial population sizes. Therefore, various lake sizes will need to be tested to determine the extinction risk for both small and large populations.

My first objective was to determine if age at 50\% maturity and length specific fecundity were density dependent for Big Crooked Lake, Wisconsin, during 1997-2003. In Chapter 1, I used linear regression to determine if age at 50\% maturity and lengthspecific fecundity were density dependent. I expected to find that both the age at $50 \%$ maturity and length-specific fecundity were related to density (Spangler et al. 1977; Colby and Nepszy 1981). The results could then be incorporated into the simulation model that will be created to answer my second objective.

My second objective was to evaluate the sustainability of walleye populations across a range of lake sizes (abundance varies with lake size) that are then subjected to ranges of exploitation rates and allocations of angling and spearing harvest (the fisheries differ greatly in size selectivity). In Chapter 2, I created an age-structured simulation model to determine if the currently agreed upon exploitation rate of $35 \%$ was sustainable. 
My results will be used to better manage the walleye populations of Wisconsin's ceded territory for a sustainable future. 


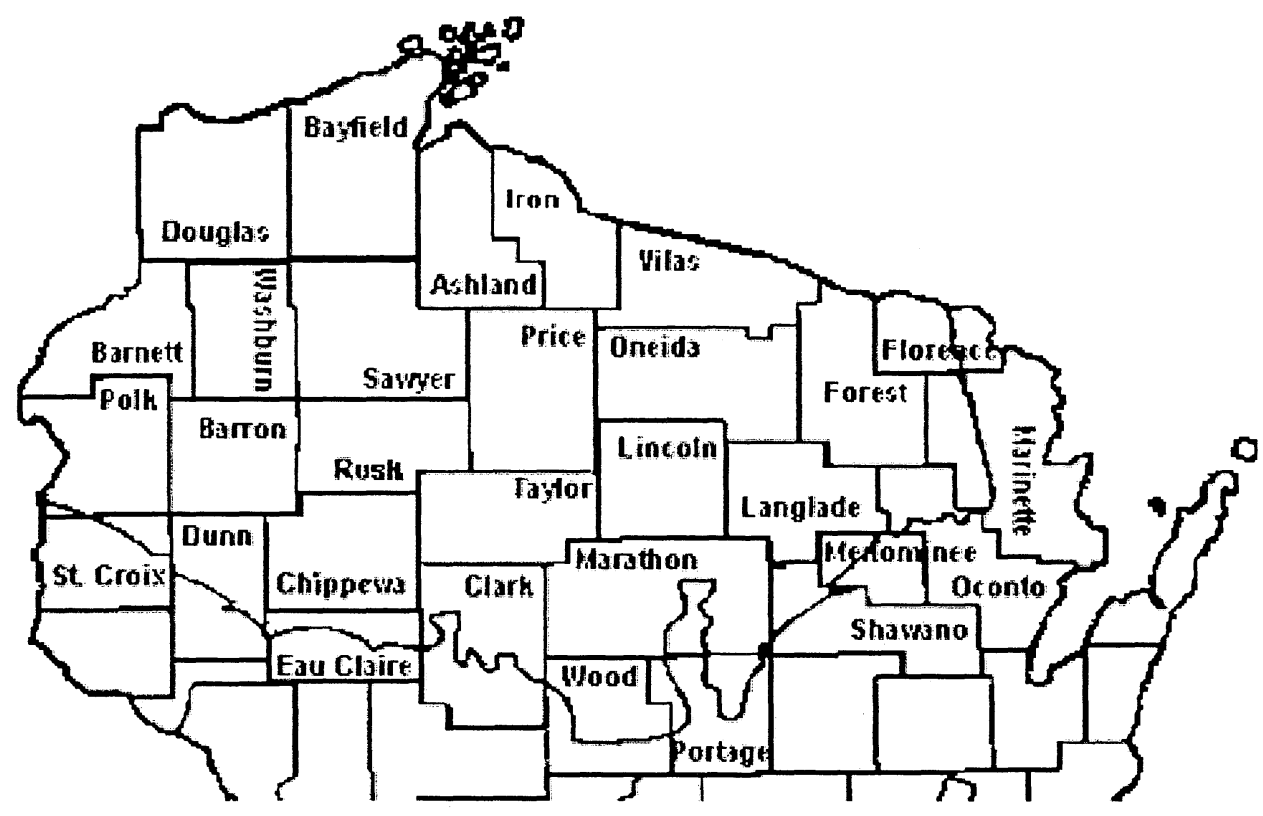

Figure 1. The ceded territory of northern Wisconsin, which is denoted by the line and includes pieces of 30 counties and 22,400 square miles. 


\section{Chapter 1:}

\section{Density Dependence of Maturity and Fecundity of Walleyes}

in Big Crooked Lake, Wisconsin, 1997-2003

Abstract.-Density is an important factor regulating age at maturity and fecundity of fish populations, so I evaluated the effect of adult walleye Sander vitreus population density on age at 50\% maturity and length-specific fecundity in Big Crooked Lake, Wisconsin, during 1997-2003. Abundance of adult walleye from mark-recapture surveys ranged from 2,046 fish ( 3 walleye/acre) to 4,901 fish (7 walleye/acre). Age at 50\% maturity ranged from 3.89 years to 4.88 years, length of walleye sampled for fecundity ranged from 13.0 in to 24.7 in, and average fecundity of a 17 -in walleye ranged from 41,061 eggs to 53,009 eggs. Age at 50\% maturity increased significantly as adult walleye population density increased, whereas average fecundity of a 17 -in walleye did not change significantly with density. Therefore, age at $50 \%$ maturity could be used as an indicator of population density and exploitation stress and thus could be used to set desired levels of harvest. 


\section{Introduction}

Population density is an important factor regulating recruitment, growth, and mortality of fishes (Spangler et al.1977; Muth and Wolfert 1986; Fox and Flowers 1990; Myers 2002), including walleye Sander vitreus. Population density may affect the growth rate of fishes, which then may affect age at maturity and fecundity (Spangler et al.1977; Baccante and Reid 1988; Muth and Ickes 1993; Trippel 1995). Density of fish populations can be regulated by biological factors such as prey abundance, cannibalism, and competition; abiotic factors such as temperature and nutrients; or human-caused factors such as exploitation (Spangler et al.1977; Muth and Wolfert 1986; Baccante and Reid 1988; Trippel 1995).

Age at maturity is related to density for some fish species, because as population density decreases, growth increases, and age at maturity decreases (Spangler et al.1977). For example, age at maturity was density dependent for Atlantic cod Gadus morhua in the Atlantic Ocean (Trippel 1995) and Atlantic sharpnose shark Rhizoprionodon terraenovae in the Gulf of Mexico (Carlson and Baremore 2003). Similarly, in Lake Erie, when the walleye population was heavily exploited and density was low, age at maturity decreased, and when exploitation declined and density increased, age at maturity increased (Muth and Wolfert 1986). Age at maturity was also related to exploitation of northern pike Esox lucius in Murray Lake, Houghton Lake, and Lac Vieux Desert in Michigan (Diana 1983).

Fecundity is sometimes related to density, because as population density decreases, growth increases, and fecundity may increase (Colby and Nepszy 1981). For example, fecundity was density dependent for cisco Coregonus artedi in Lake Superior 
(Bowen et al. 1991) and for orange roughy Hoplostethus atlanticus in Australian waters of the Pacific Ocean (Koslow et al. 1995). Fecundity may be regulated by exploitation, because walleye fecundity increased after controlled exploitation began in two Canadian lakes (Baccante and Reid 1988). Fecundity also responded to exploitation of lake trout Salvelinus namaycush (Healey 1978).

My objective was to determine if age at maturity and fecundity of walleye was related to population density in Big Crooked Lake in Vilas County, Wisconsin, during 1997-2003. I then sought to evaluate the use of age at maturity and fecundity as indicators of abundance. Big Crooked Lake is part of a larger study to evaluate effects of increased exploitation. A $35 \%$ exploitation rate was instituted on the walleye population in Big Crooked Lake by purposefully removing $35 \%$ of the adult population each year. Population abundance was estimated in spring of each year, and the number of fish harvested throughout the year was recorded through a creel census. In the next spring, if $35 \%$ of the adult walleye population had not been harvested in the previous year, more fish were removed until $65 \%$ of the adult walleye population remained. Therefore, an induced decline in the adult walleye density in Big Crooked Lake allowed us to test if maturity and fecundity could be used as indicators of population density.

\section{Methods}

Big Crooked Lake is located in Vilas County, Wisconsin on the property of Dairymen's Incorporated, and is a private, soft-water, drainage lake of approximately 682 acres (Serns 1978; Short 2001; Hansen et al. 2004). The shoreline of the lake is $5.03 \mathrm{mi}$ and includes two islands. Big Crooked Lake is an oligotrophic lake with a maximum depth of $38 \mathrm{ft}$. Total alkalinity was approximately $14 \mathrm{mg} / \mathrm{L}$, conductivity was 
approximately $39 \mu \mathrm{S} / \mathrm{cm}$ at $25^{\circ} \mathrm{C}$, and $\mathrm{pH}$ was 7.2 (Hansen et al. 2004). Total nitrogen was $0.69 \mathrm{mg} / \mathrm{L}$ and total phosphorus was $0.03 \mathrm{mg} / \mathrm{L}$ during turnover (Serns 1978). The lake is mostly undeveloped except for a few cabins located on the northern shore. Substrate consists mostly of sand, gravel, and rock. Fish species prominent in the catch include walleye, muskellunge Esox masquinongy, northern pike, smallmouth bass Micropterus dolomieu, yellow perch Perca flavescens, rock bass Ambloplites rupestris, mimic shiners Notropis volucellus, and white suckers Catostomus commersonii.

The adult walleye population was surveyed by mark-recapture in Big Crooked Lake each year during 1997-2003. Walleye were collected for marking in fyke nets with $3.9 \mathrm{ft}$ frames and 0.75 in square mesh immediately after ice-out in April or early May. Adult walleye were identified as fish with externally visible gametes or fish greater than or equal to 15.0 in (Beard et al. 2003a) and were marked by removal of a fin or with monel metal jaw tags and released. The recapture sample came from a combination of a mandatory creel census, gillnetting, and electrofishing from ice-out until June. A mandatory creel census on the lake ensured that every fish was checked by a dock attendant. Gill nets were 200, 250, and $300 \mathrm{ft}$ long, $6 \mathrm{ft}$ high, and were set on the bottom with a soak time of three to four hours. Gill-net twine was either nylon or monofilament, and the monofilament had a twine size of $0.01 \mathrm{in}$. Gill nets ranged from 2.5 to $4.5 \mathrm{in}$ stretch measure and had a hanging ratio of 0.5 (length of the supporting rope divided by the stretched length of the netting; Hayes et al. 1996). Electrofishing was from a boatmounted 230-V AC unit with two booms and three dropper electrodes (Hansen et al. 2004). The electrofishing boat was run as close to shore as possible, around the entire shoreline and islands, at night during spring spawning. Crews consisted of one operator 
and two netters, and the speed of the boat was $1.4-1.6 \mathrm{mi} / \mathrm{h}$. I assumed the recapture sample was random because all anglers were interviewed for the creel census, angling was throughout the lake, and the entire shoreline of the lake was electrofished. Adult walleye were vulnerable to capture in all gear types. Population abundance was estimated for adult male and female walleye with Chapman's modification of the Petersen estimator (Ricker 1975). I estimated 95\% confidence intervals for markrecapture estimates of abundance using formulas for exact $95 \%$ confidence intervals for the binomial proportion of marked individuals in recapture samples (formulas 24.28 24.29, Zar 1999).

Age at maturity was estimated for female walleye from angler-caught fish observed during a mandatory creel census and from gillnet-caught fish during sampling. Walleye caught by anglers from the first Saturday in May to the third week in June were examined for maturity by a Wisconsin Department of Natural Resources employee. Gill nets were the same as those used for mark-recapture surveys. Maturity was estimated by examining the gonads. Ages of fish shorter than 20 in were estimated from scale samples and ages of fish longer than 20 in was estimated from spine samples. Seale-age estimates were compared to fish of known age and with fish of partial known age (Devries and Frie 1996). Fish of known age were marked with a permanent fin clip at age-0, and the fin clip given changed yearly on a four-year cycle. Fish of partial-known age were fish that were tagged at a younger age estimated from a scale sample.

The mean age at $50 \%$ maturity $\left(X_{m}\right)$ was estimated for the walleye population in each year during 1997-2003 from the nonlinear relationship between the proportion of mature females in each class, $M_{x}$, and age, $X$ : 


$$
M_{x}=\frac{1}{1+e^{-r\left(X-X_{m}\right)}}
$$

where $M_{x}$ is a variable that describes the proportion of mature females as a function of age $X, r$ is a parameter that describes the degree of curvature in the relationship between maturity $M_{x}$ and age $X$, and $X_{m}$ is a parameter that describes the inflection point in the curve, the mean age at 50\% maturity (Quinn and Deriso 1999). I estimated the parameters, $r$ and $X_{m}$, and their asymptotic standard errors and approximate $95 \%$ confidence intervals, from data on the proportion of mature females $M_{x}$ in each age class $X$ for each year of sampling using a Gauss-Newton numerical search method with additive errors (Systat 2004).

Fecundity was estimated for individual fish sampled from early March to early May during 1997-2003. Fish were collected through the mandatory creel census, fyke netting, and electrofishing, as described above. Total length (TL) was measured to the nearest $0.1 \mathrm{in}$, and weight was measured to the nearest $0.01 \mathrm{lb}$. Scales were removed from each fish to estimate age as above. Ovaries were removed, wrapped in cheesecloth, and placed in a $10 \%$ formalin solution. Prior to examination, each ovary was rinsed, blotted dry, and weighed to the nearest $0.00035 \mathrm{oz}$. A cross-section of the right ovary was taken from the medial section because this section has the least-associated error (Serns 1982). Each cross-section was weighed to the nearest $0.00035 \mathrm{oz}$, and the eggs in the cross-section were counted. The number of eggs in the entire ovary was then estimated from direct proportion by weight (Serns 1982).

The mean fecundity of a 17-in walleye was estimated for each year from the linear relationship between $\log _{e}\left(\right.$ fecundity) and $\log _{e}($ length): 


$$
\log _{e}(\text { fecundity })=\log _{e}(\alpha)+\beta \log _{e}(\text { length })
$$

where $\log _{e}(f e c u n d i t y)$ is a variable for the number of eggs estimated for individual female walleye sampled, $\log _{e}($ length $)$ is a variable for length of individual female walleye sampled, $\alpha$ is a parameter for the slope of the relationship near the origin, and $\beta$ is the change in the slope with length for the allometric relationship between fecundity and length. The mean fecundity of a 17-in walleye was used as an index of fecundity because 17 in was the mean length of female walleye in the fecundity sample. The $\pm 95 \%$ confidence intervals for mean fecundity of a 17-in female walleye were estimated as the prediction interval for an estimated Y (Zar 1999).

Linear regression was used to determine if age at maturity or fecundity were related to adult walleye population density. First, I tested for density dependence of maturity by linear regression of the annual estimates of mean age at $50 \%$ maturity in each year, $X_{m}$, against adult walleye population density (number/acre) in each year. Adult walleye population density was also regressed against the age at $50 \%$ maturity of the next year to account for a one year time lag. Next, I tested for density dependence of fecundity by linear regression of the mean fecundity of a 17-in walleye against adult walleye population density (number/acre). The adult walleye population density was also regressed against the mean fecundity of a 17 -in walleye of the next year to account for a one year time lag. I concluded that maturity or fecundity were density dependent if the slope of either line was significantly different than zero $(P \leq 0.05)$ and density independent if the slope of the line was not significantly different than zero $(P>0.05)$.

If age at maturity or fecundity were significantly related to density, I tested relationships between growth and maturity or fecundity, and used inverse prediction to 
estimate density from either age at maturity or fecundity. First, if density was related to age at maturity or fecundity, mean length at age 3 , an index of growth in each year, was regressed against adult walleye density (number/acre) to test for density dependence of growth. Next, adult walleye population density was regressed against mean length at age 3 in the next year to account for a one year time lag. Next, if mean length at age 3 was significantly related to density, then mean length at age 3 was regressed against age at maturity or fecundity to determine if variation in growth caused the variation in age at maturity or fecundity. Last, if age at maturity or fecundity was related to population density, I used inverse prediction to estimate density from either age at maturity or fecundity (Zar 1999).

\section{Results}

Population estimates, densities, age at 50\% maturity, and fecundity of 17 -in walleye varied widely in Big Crooked Lake during 1997-2003 (Figure 2). Adult walleye abundance ranged from 2,046 to 4,901 walleye, and adult walleye population density ranged from 3.00 to 7.19 adult walleye per acre. Age at $50 \%$ maturity ranged from 3.89 to 4.88 years. The length of walleye used in the fecundity sample ranged from 13.0 to 24.7 in and averaged 17.1 in $(\mathrm{SD}=2.4 \mathrm{in})$. Fecundity for a 17 -in walleye ranged from 41,061 to 53,009 eggs.

Age of walleye at $50 \%$ maturity was positively related to adult walleye population density in Big Crooked Lake during 1997-2003 $\left(F_{1,5}=111.08 ; P<0.001\right.$; Figure 3). The age at $50 \%$ maturity decreased from 4.9 to 3.9 years as the walleye population density decreased from 7.19 to 3.00 walleye per acre. Age at $50 \%$ maturity in the next year was not significantly related to adult walleye population density $\left(F_{1,4}=3.63 ; P=0.13\right.$; Figure 
3). Population density increased from 2.1 walleye per acre to 7.5 walleye per acre as age at $50 \%$ maturity increased from 3.75 years to 5.0 years, based on the inverse prediction model (Figure 4). Length at age 3, an index of growth, was significantly related to adult walleye population density $\left(F_{1,5}=9.20 ; P=0.03\right.$; Figure 5$)$ and to age at $50 \%$ maturity $\left(F_{1,5}=13.81 ; P=0.01 ;\right.$ Figure 6$)$. Similarly, length at age 3 in the next year was also significantly related to adult walleye population density $\left(F_{1,4}=9.33, P=0.04\right.$; Figure 5$)$.

Fecundity of a 17 -in walleye was not significantly related to adult walleye population density in Big Crooked Lake during 1997-2003 $\left(F_{1,5}=0.39 ; P=0.56\right.$; Figure 7). Fecundity varied without trend from 41,061 to 53,009 eggs as walleye population density decreased from 7.19 to 3.00 walleye per acre. Fecundity of a 17 -in walleye in the next year was not significantly related to adult walleye population density $\left(F_{1,4}=0.17 ; P\right.$ $=0.70 ;$ Figure 7).

\section{Discussion}

I found that age at maturity decreased as walleye population density decreased in Big Crooked Lake, which is similar to other studies. Trippel (1995) and Carlson and Baremore (2003) found that a decrease in age at maturity coincided with a decrease in density for Atlantic cod in the Atlantic Ocean and for Atlantic sharpnose shark in the Gulf of Mexico, respectively, which suggests that age at maturity is density dependent. Carlson and Baremore (2003) and Wolfert (1969) found that a decrease in age at maturity coincided with an increase in growth rates for Atlantic sharpnose shark in the Gulf of Mexico and for walleye in Lake Erie, respectively, therefore growth may be the mechanism by which age at maturity changes with density. Age at maturity was related to exploitation for northern pike in Murray Lake, Houghton Lake, and Lac Vieux Desert 
in Michigan (Diana 1983) and for walleye in Lake Erie (Muth and Wolfert 1986). If age at maturity is regulated by changes in density that can be caused by exploitation, then age at maturity would be a good indicator of overexploitation. Therefore, age at maturity could be used to manage the walleye fishery in Big Crooked Lake, Wisconsin, because age at maturity is an indicator of population density. My results are promising, but confirming the relationship over a broader range of population density would help to define the shape of the relationship between population density and age at maturity. Other factors also influence population density, so density and age at maturity may change independently of exploitation in other systems.

I found that walleye fecundity was not significantly related to walleye population density in Big Crooked Lake, which is in contrast to findings for other studies where increasing fecundity coincided with decreasing population density for cisco in Lake Superior (Bowen et al. 1991) and orange roughy in Australian waters of the Pacific Ocean (Koslow et al. 1995). However, average fecundity may be related to population density over a broader range of population density than observed in my study. Alternatively, other studies have shown that feeundity was more strongly related to factors other than population density. For example, fecundity may be related to prey availability, rather than population density, as was found for brown trout Salmo trutta (Bagenal 1969) and rainbow trout Oncorhynchus mykiss (Scott 1962). Fecundity may also vary one year later than population density, because walleye develop their eggs in the fall of the previous year and therefore depend on energy acquired during the preceding summer (Nikolskii 1969; Henderson and Morgan 2002), though I found that walleye fecundity in the next year was not related to walleye population density. 
Fecundity may depend on the level of intraspecific and interspecific competition for prey (Baccante and Reid 1988). If density of a species declines, then intraspecific competition would decline, or if density of competing species declines, then the level of interspecific competition would decline, and in either case, a lower level of competition may result in a greater number of available prey per individual. This in turn would allow individual fish to dedicate more of their energy intake to producing eggs and would result in higher fecundity. Last, fecundity may vary because older female percids may not spawn every year (Henderson et al. 2000), and walleye fecundity may be inversely related to egg size because younger fish spawn as if semelparous and older fish spawn as if iteroparous (Henderson and Nepszy 1994). Therefore, if not all older females spawn and egg size varies, population fecundity may vary over time with density. The large variation in estimates of fecundity could be due to sources of error in the cross-sectional sampling method used for estimating fecundity.

Yearly changes in age at maturity could be used to set harvest levels for Big Crooked Lake, Wisconsin, because yearly changes in age at maturity reflected yearly changes in walleye population density. To use my model for age at maturity as a predictor of population density in other lakes, the relationship between population density and age at maturity would need to be verified. Population density could be estimated by mark-recapture or another method, and age at maturity could be estimated from samples of gonads and ages obtained during creel or fishery surveys. Inverse prediction (Zar 1999) could then be used to estimate population density from age at maturity with as much precision as population density can be estimated from mark-recapture surveys, as I found. Harvest regulations could then be adjusted to achieve the desired population 
density. Age at maturity could also be used as an indicator of exploitation stress. If age at maturity for a population decreased, the harvest rate could be lessened to reduce exploitation stress on the population. In contrast to age at $50 \%$ maturity, fecundity is a poor indicator of density, so should not be used to index exploitation stress or to predict density without further study over a broader range of walleye population density. 

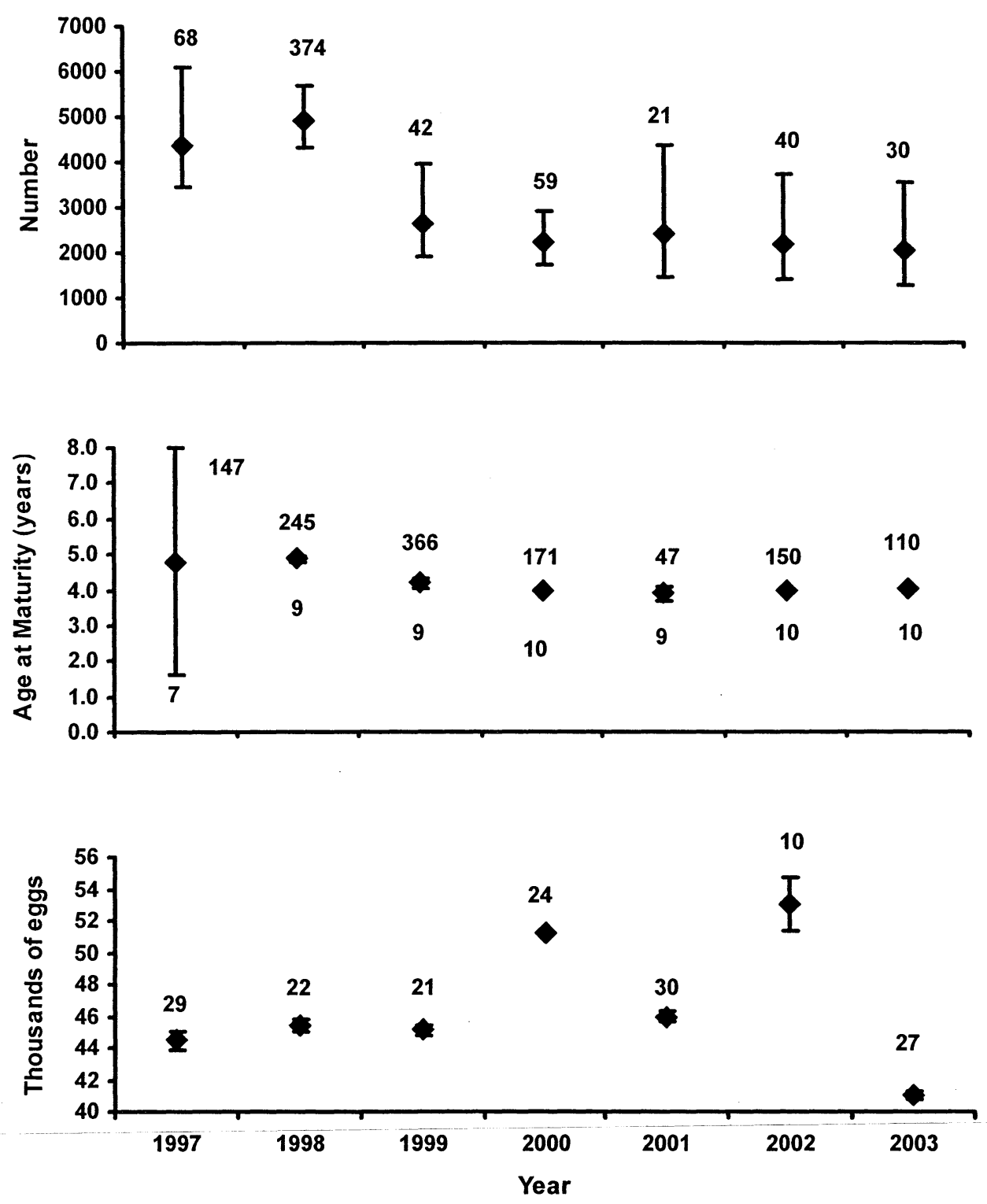

Figure 2. Adult abundance (upper panel), age at 50\% maturity (middle panel), and fecundity (lower panel) during 1997-2003 ( \pm 95\% confidence interval) of walleye in Big Crooked Lake, Wisconsin. Numbers above abundance estimates are numbers of recaptures in each year, numbers above age at $50 \%$ maturity are numbers of fish for each year, and numbers below age at $50 \%$ maturity and above fecundity estimates are sample sizes in each year. 

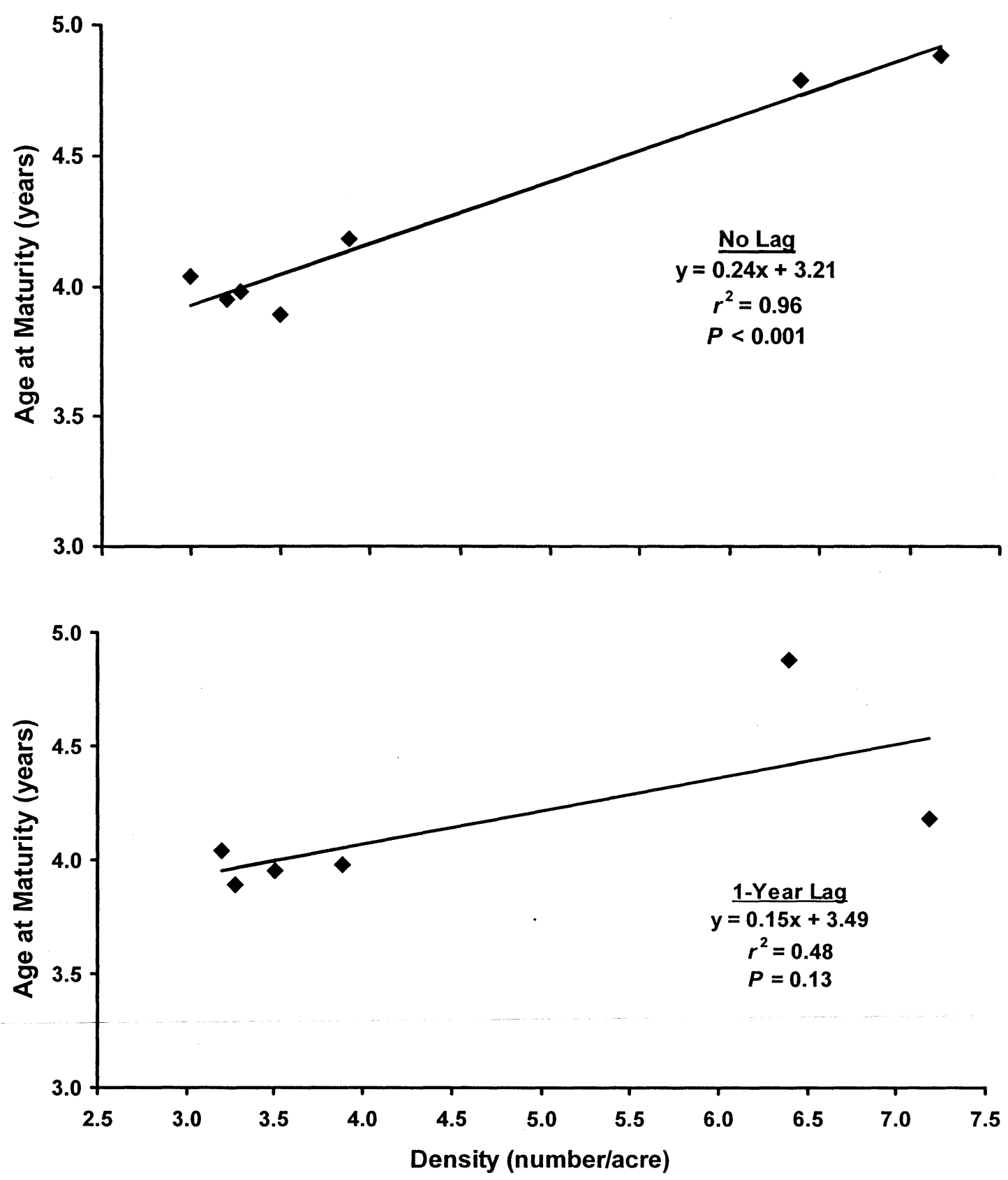

Figure 3. Age at 50\% maturity versus adult population density (upper panel) and age at $50 \%$ maturity versus adult population density in the previous year (lower panel) for walleye in Big Crooked Lake, Wisconsin, during 1997-2003. 


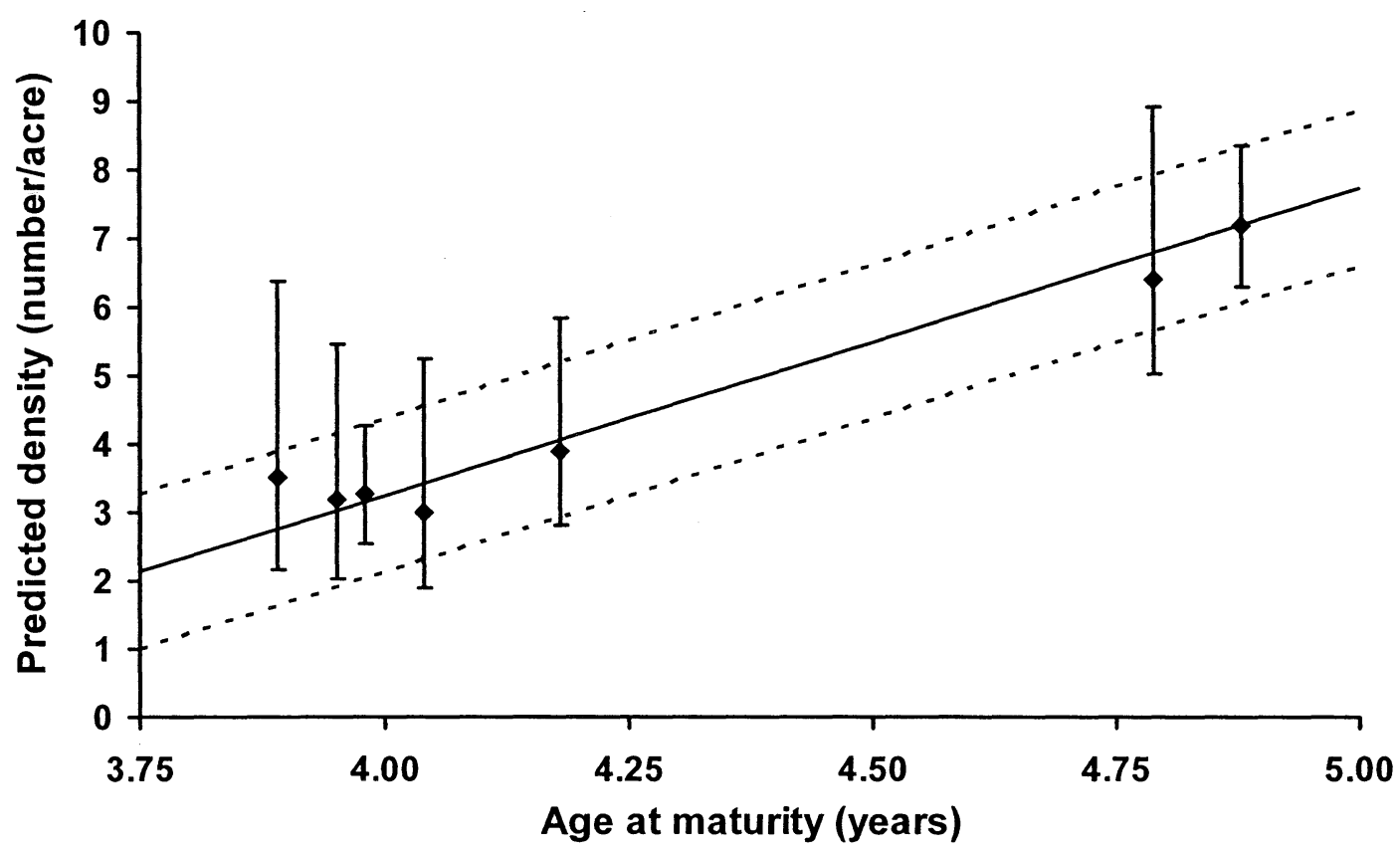

Figure 4. Observed (error bars $= \pm 95 \%$ confidence interval) and predicted adult walleye population density (regression line $\pm 95 \%$ prediction interval) versus age at $50 \%$ maturity for walleye in Big Crooked Lake, Wisconsin during 1997-2003. 

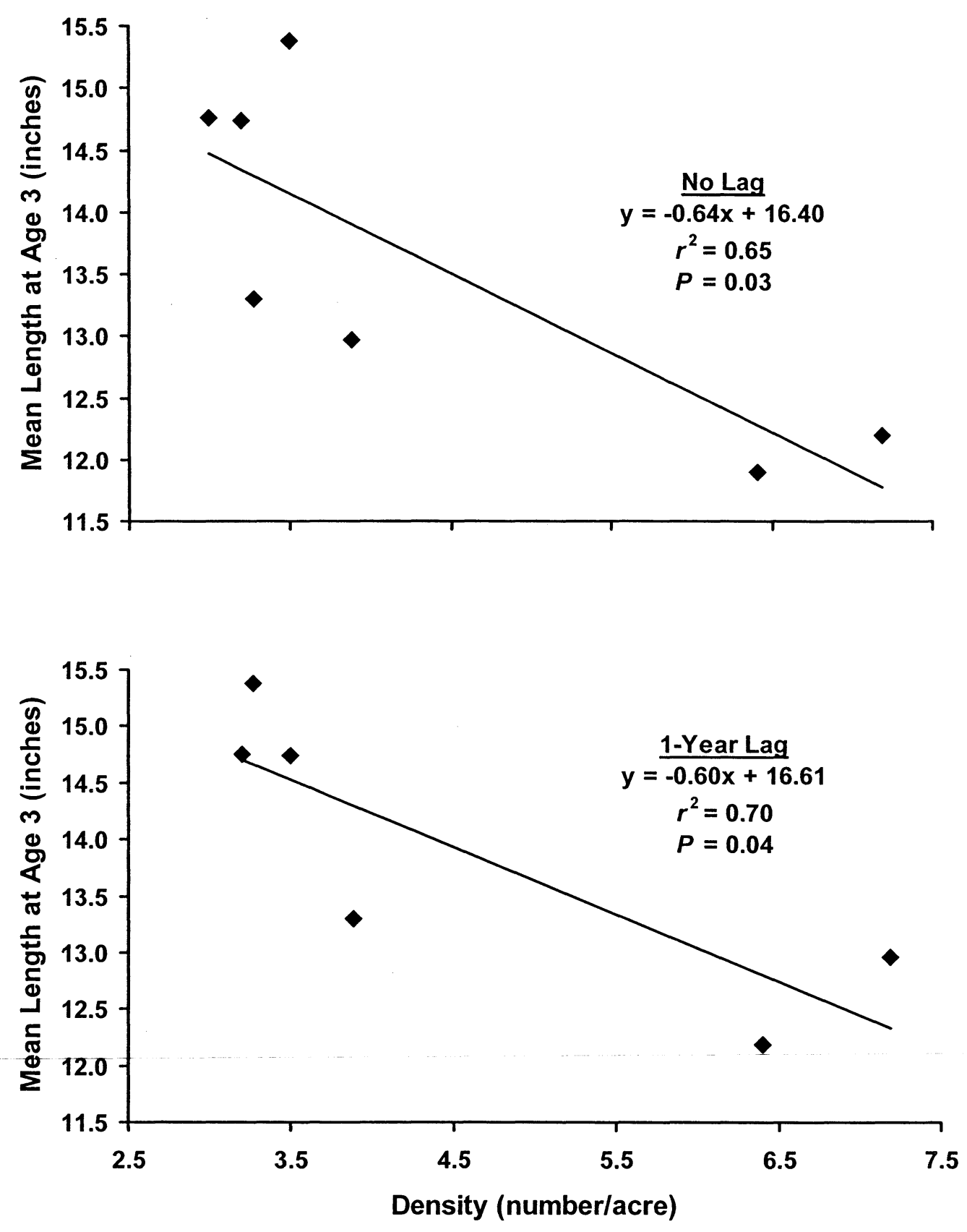

Figure 5. Mean length at age 3 versus adult population density (upper panel) and mean length at age 3 versus adult population density in the previous year (lower panel) for walleye in Big Crooked Lake, Wisconsin, during 1997-2003. 


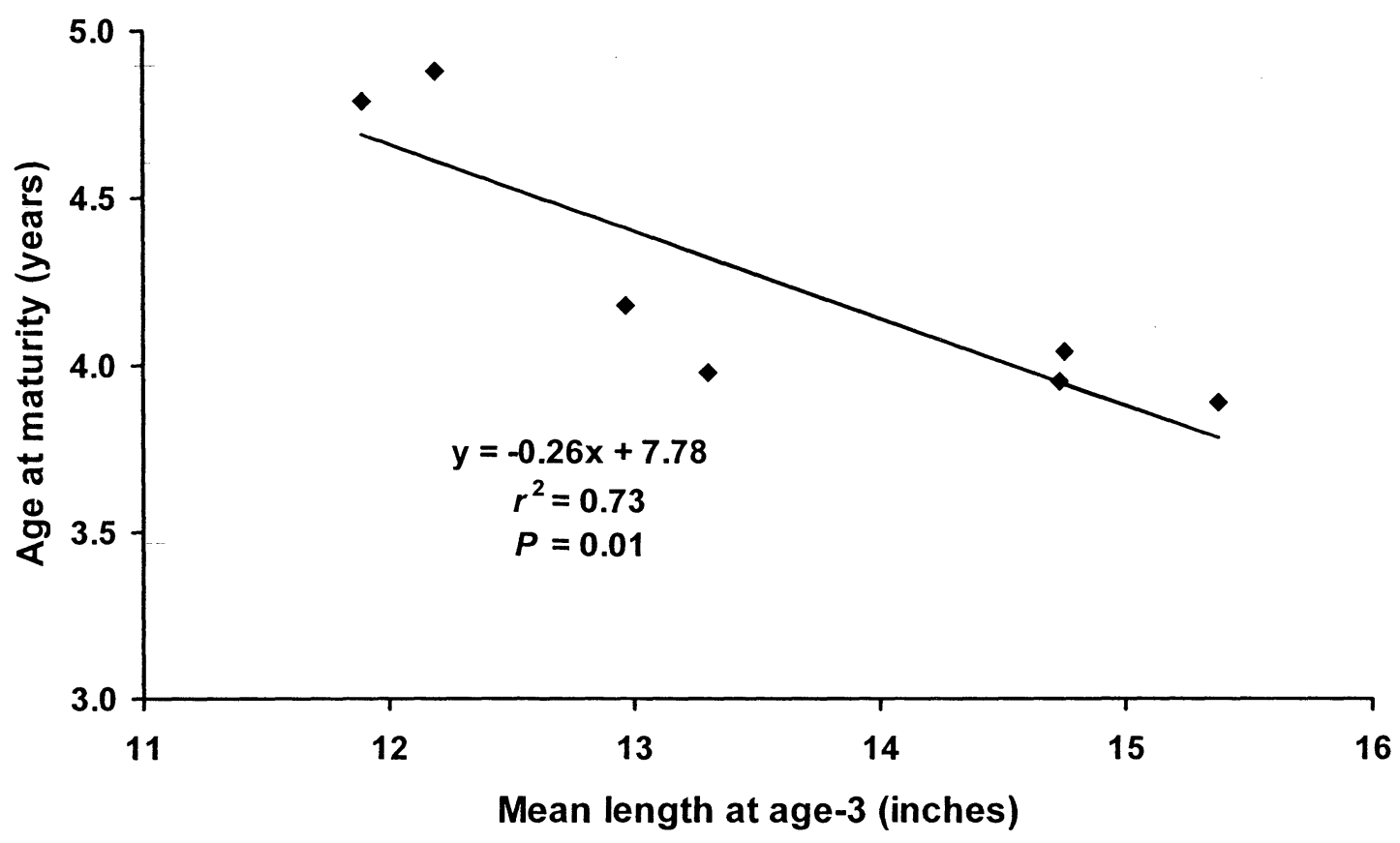

Figure 6. Age at 50\% maturity versus mean length at age 3 for walleye in Big Crooked Lake, Wisconsin, during 1997-2003. 

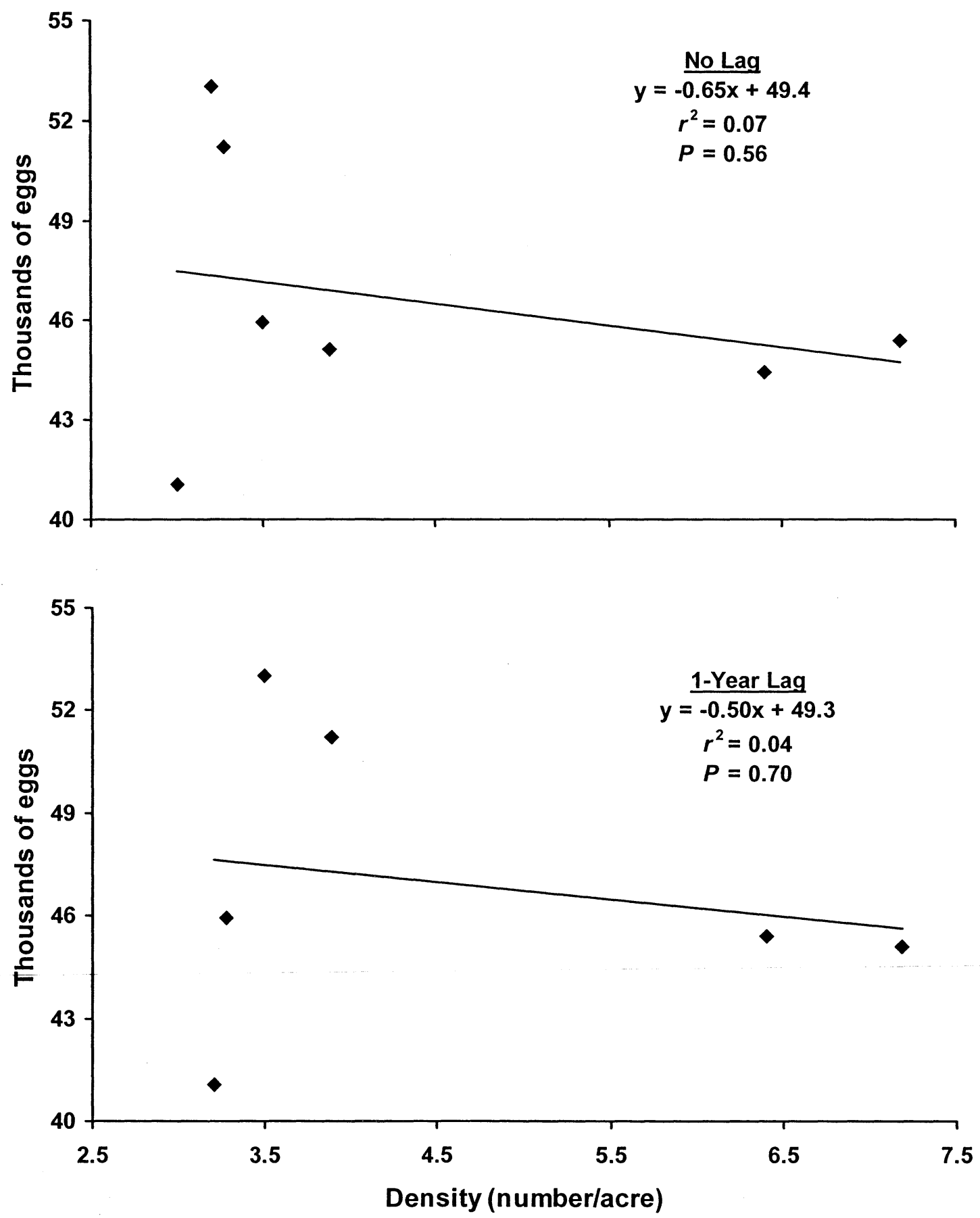

Figure 7. Mean fecundity of a 17-in walleye versus adult population density (upper panel) and mean fecundity of a 17 -in walleye versus adult population density in the previous year (lower panel) for walleye in Big Crooked Lake, Wisconsin, during 1997-2003. 


\section{Chapter II:}

\section{Simulating the Sustainability of Walleye}

\section{Populations in Northern Wisconsin Lakes}

Abstract. - Walleye population sustainability in the face of state angling and tribal spearing fishery harvest has been an issue in Wisconsin's ceded territory since a Federal District Court affirmed the rights of Native Americans to hunt and fish off reservation. My objective was to evaluate the sustainability of walleye populations across a range of lake sizes (abundance varies with lake size) that are then subjected to ranges of exploitation rates and allocations of angling and spearing harvest (the fisheries differ greatly in size selectivity). To meet this objective, I developed an age-structured population model for estimating extinction risk and time to extinction for a hypothetical walleye population at a specified exploitation rate, fishery allocation, and initial abundance. The age-structured population model was parameterized from intensive surveys of walleye populations in Escanaba Lake and extensive surveys of walleye populations in northern Wisconsin lakes. Simulations covered a range of annual exploitation rates that included the currently-accepted rate of $35 \%$ and a range of population sizes that are presently included in regression models that relate walleye abundance to lake surface area. The risk of extinction began to increase above zero at an exploitation rate of $56-61 \%$ for an unregulated angling fishery, $73-76 \%$ for an angling fishery with a 15 in minimum length limit, and $75-80 \%$ for a spearing fishery. The probability of decline began to increase above zero at an exploitation rate of $47 \%$ for an unregulated angling fishery, $60 \%$ for an angling fishery with a 15 in minimum length limit, and $60 \%$ for a spearing fishery. As the exploitation rate increased, the average 
adult abundance decreased and the time to extinction decreased for all lake sizes and initial population sizes. I conclude that the current maximum exploitation rate of $35 \%$ is sustainable for all lake sizes and initial population sizes and that angler daily bag limits and spearing quotas could be increased while still ensuring the sustainability of walleye populations. However, steps should be taken to implement a field experiment to verify the results of the simulation model before the results are used for management. 


\section{Introduction}

The walleye Sander vitreus is the most highly sought fish species in angling and spearing fisheries of northern Wisconsin (BIA 1991; McClanahan 2003), where tribes retain rights to hunt, fish and gather natural resources off reservation (BIA 1990; Staggs et al. 1990; Beard et al. 2003b). The Wisconsin Department of Natural Resources (WDNR) and the Great Lakes Indian Fish and Wildlife Commission (GLIFWC) jointly manage walleye populations in northern Wisconsin using a maximum annual exploitation rate of $35 \%$ of the adult population, which was agreed upon by state and tribal biologists as sustainable, based on past data (BIA 1991). However, the sustainability of a $35 \%$ exploitation rate on adult walleye has never been evaluated.

Walleye fisheries in northern Wisconsin are regulated through lake-specific spearing quotas and angling bag limits (Staggs et al. 1990). Each year, the six Lake Superior Chippewa tribes notify the Wisconsin Department of Natural Resources, by 15 March, how many fish they intend to harvest from each lake. The quota on each lake is the number of fish that can be harvested based on a $35 \%$ exploitation rate and estimate of abundance. For past estimates of abundance, quotas include safety factors to account for temporal changes in abundance from the time when the abundance was estimated to the time when the estimate is used (Hansen et al. 1991). For other lakes, quotas are set based on the relationship between adult walleye abundance and lake size (Nate et al. 2000; Staggs et al. 1990). The angling fishery is regulated through a bag-limit system that responds to tribal quota declarations, by adjusting bag limits on individual lakes to account for tribal harvest. Angling occurs from the first Saturday in May to March of the following year (Beard et al. 2003a). Tribal and state harvest is regulated so as not to 
exceed the $35 \%$ maximum exploitation rate more than 1 in 40 times (Hansen et al. 1991), which means that an estimated $2.5 \%$ of the ceded territory's lakes remain at risk of overexploitation.

Sustainable exploitation rates may vary among lakes due to factors that predispose a population to an increased extinction risk or risk of decline. Extinction risk and probability of decline to some threshold level are often used as criteria for sustainable biological resources (Hakoyama and Iwasa 2000). One factor that predisposes a population to an increased risk of extinction or decline is a small initial population size (Ricklefs 1983; Pimm et al. 1988; Tracy and George 1992). Having different exploitation rates for various lake sizes may be necessary to reduce extinction risk and risk of decline because small lakes with small initial population sizes may require a lower exploitation rate than large lakes with large initial population sizes.

My objective was to evaluate the sustainability of walleye populations across a range of lake sizes (abundance varies with lake size) that are then subjected to ranges of exploitation rates and allocations of angling and spearing harvest (the fisheries differ greatly in size selectivity). Sustainability of walleye populations subjected to spearing and angling harvest was evaluated using an age-structured, density-dependent, stochastic simulation model. The age-structured population model was parameterized from intensive surveys of walleye populations in Escanaba Lake and extensive surveys of walleye populations in northern Wisconsin lakes. Recruitment and natural mortality submodels provided density dependent feedback and included parameter uncertainty as random error. Simulations of age-specific abundance in future years covered a range of age-specific abundance at varying levels of spearing and angling exploitation. 


\section{Methods}

Data used to construct the model came from extensive surveys of walleye in lakes in northern Wisconsin or intensive surveys of walleye in Escanaba Lake, which has been a long term research lake since 1946 and is also located in the ceded territory (Kempinger et al. 1975). The ceded territory of Wisconsin is the northern one-third of Wisconsin, includes pieces of 30 counties, and 22,400 square miles (BIA 1991; BIA 2003). Lakes in the ceded territory range in size from less than 100 to over 10,000 acres, and each year, about 25 treaty lakes are randomly selected for monitoring (Hansen et al. 2000; Nate et al. 2001; Beard et al. 2003a). Creel survey data are collected from the first Saturday in May through March 1 of the following year, and anglers are surveyed using a stratified random creel design (Fayram 2003). Creel clerks survey all weekend days and holidays and three randomly sampled weekdays each week. Clerks record effort, catch, harvest, and lengths and markings of harvested fish. A clerk is on-site at each lake that is speared during the spearing season to record the effort, harvest, lengths, and marks of harvested fish (Staggs et al. 1990). Walleyes are the primary target species in treaty lakes (Beard et al. 2003b), but other commonly sought species include muskellunge Esox masquinongy, yellow perch Perca flavescens, northern pike Esox lucius, smallmouth bass Micropterus dolomieu, largemouth bass Micropterus salmoides, bluegill Lepomis macrochirus, pumpkinseed Lepomis gibbosus, black crappie Pomoxis nigromaculatus, rock bass Ambloplites rupestris, and black bullhead Ictalurus melas (BIA 1991).

From a starting abundance at age $j, N_{i j}$ at the start of each simulation, $i=0$, the abundance at age for the next year was estimated as:

$$
N_{i+1, j+1}=N_{i j} e^{-Z_{i j}}
$$


where $N_{i+1, j+1}$ is the number of walleyes surviving in each age class $j$ and year $i$ to the next age class $j+1$ and year $i+1, N_{i j}$ is the number of walleyes in age class $j$ and year $i$, and $Z_{i j}$ is the total rate of instantaneous mortality for each age class $j$ in year $i$ (Quinn and Deriso 1999; Haddon 2001; Figure 8). The age specific abundance $N_{i j}$ was an input for year zero and was taken from the lower prediction interval for population size based on lake size. This value was then apportioned into age classes based on average numbers in each age class from Escanaba Lake during 1980-2001.

The total instantaneous mortality rate $Z_{i j}$ for each age $j$ and year $i$ was treated as a combination of total instantaneous natural mortality $\left(M_{i}\right)$ in year $i$ and total instantaneous fishing mortality $\left(F_{i j}\right)$ for each age $j$ in year $i$ :

$$
Z_{i j}=F_{i j}+M_{i}
$$

The total instantaneous fishing mortality $\left(F_{i j}\right)$ was simulated using a selectivity curve for each fishery and a fully-selected fishing mortality rate that was specified as a model input:

$$
F_{i j}=s_{j} F_{i}
$$

where $s_{j}$ is the selectivity of the gear for age $j$ and $F_{i}$ is the fully-selected fishing mortality specified for the simulation in each year $i$. Selectivity $\left(s_{j}\right)$ was estimated for angling and spearing fisheries from average age-specific catches at age $j, C_{j}$, and abundances at age $j$, $N_{j}$, in treaty lakes and in Escanaba Lake $\left(s_{j}=C_{j} / N_{j}\right)$. Relative selectivity $\left(S_{j}\right)$ was then estimated as the age-specific selectivity divided by the maximum age-specific selectivity $\left[S_{j}=s_{j} / \max \left(s_{j}\right)\right]$. The angling selectivity curve for no regulations was estimated from angling and abundance data for Escanaba Lake during 1980-2000, where angling was unregulated. The angling selectivity curve for a 15 in minimum length limit was 
estimated from statewide growth summaries for walleye and then setting selectivity at the age when 15 in was attained for fish in northern Wisconsin. The spearing selectivity curve was estimated from spearing and abundance data from lakes in the ceded territory during 1999-2003. Relative selectivity $\left(S_{j}\right)$ for each of the fisheries was modeled as:

$$
S_{j}=\frac{1}{1+e^{-\ln 19\left[\frac{j-j_{50}}{j_{95}-j_{50}}\right]}}
$$

where $j$ is the age, $j_{50}$ is the age at $50 \%$ selectivity, and $j_{95}$ is the age at $95 \%$ selectivity (Haddon 2001). The angler exploitation rate $u_{A}$ and the spearing exploitation rate $u_{S}$ were both specified as model inputs. Each of the exploitation rates $\left(u_{A}\right.$ or $\left.u_{S}\right)$ was converted to an approximate instantaneous fishing mortality rate $\left(\mathrm{F}_{i}\right)$ :

$$
F_{i}=-\ln (1-u)
$$

For example, when the angler exploitation rate was $35 \%$ and the spearing exploitation rate was $0 \%$, the total instantaneous fishing mortality $\left(F_{i}\right)$ in year $i$ was approximately 0.43 (Haddon 2001).

Total instantaneous natural mortality was estimated for each year from the density of age-3-and-older walleye in that year:

$$
M_{i}=0.0136+0.0853 D_{i, j=3+}+\varepsilon
$$

where $M_{i}$ is the total instantaneous natural mortality for year $i, 0.0136$ is the intercept of the regression line, 0.0853 is the slope of the regression line, $D_{i, j=3+}$ is the density of walleyes present in year $i$ at ages three and greater (number/acre), and $\varepsilon$ is additive process error. The slope, intercept, and process-error parameters were estimated using a statistical catch-at-age model from angling catches at age, abundance at age, and 
recruitment at age-0 from Escanaba Lake during 1956-2001 (M. J. Hansen, University of Wisconsin-Stevens Point, unpublished data). The process-error term, which incorporated stochasticity into the model for the natural mortality equation, was estimated by trial-anderror until the simulated range of natural mortality rates mimicked the observed range of natural mortality rates.

Next, the number of age- 0 walleyes $\left(N_{i, j=0}\right)$ recruited to the population in each year was predicted using a Ricker stock-recruitment model (Ricker 1975). Spawner abundance was the number of sexually mature female fish in the population, and the stock-recruitment model was parameterized from the equation:

$$
N_{i, j=0}=\alpha\left(N_{i, j} M_{j}\right)\left(e^{-\beta N_{i, j} M_{j}}\right) e^{\varepsilon}
$$

where $N_{i, j=0}$ is the number of age- 0 walleyes to enter the population in year $i, \alpha$ is the recruits per spawner at low spawner abundance, $N_{i, j}$ is the female abundance in year $i$ at age $j, M_{j}$ is the proportion of females of age $j$ that are sexually mature, $\beta$ is the instantaneous rate at which recruits/spawner declines with spawner abundance, and $e^{\varepsilon}$ is multiplicative process error. Model parameters $\alpha$ and $\beta$ and process error were estimated numerically from data on Escanaba Lake during 1980-2001. Density dependence was incorporated into the recruitment sub-model, by dividing parameter $\beta$ by the population density (Ricker 1975). For each year of the simulation, the proportion of fish mature at age $j\left(M_{j}\right)$ was determined by:

$$
M_{j}=\frac{1}{1+e^{\left(-r\left(j-j_{50}\right)\right)}}
$$

where $r$ is a parameter that describes the degree of curvature in the relationship between maturity $M_{j}$ and age $j$, and $j_{50}$ is a parameter that describes the inflection point in the curve, 
the mean age at 50\% maturity (Quinn and Deriso 1999). To determine the proportion of fish mature at each age $j, j_{50}$ was set to a random value based on a normal curve with the mean set to the mean age at 50\% maturity for Escanaba Lake and the standard deviation set to the standard deviation of the age at 50\% maturity for Escanaba Lake during 1980 2001, and $r$ was set to a random value based on a normal curve with the mean set to the mean $r$ and the standard deviation set to the standard deviation of $r$ for Escanaba Lake during 1980-2001.

The model was evaluated using local sensitivity analysis, which is a method often used to quantify uncertainty for a simulation model (Cross and Beissinger 2001; Ellner and Fieberg 2003). A local sensitivity analysis was performed by holding all of the parameters at a mean constant value and changing one parameter at a time by a specified amount to determine which parameters most strongly influenced model predictions (McCarthy et al. 1996; Essington 2003). The sensitivity of the model to a parameter change was expressed as the difference in the mean population level when the parameter was changed, compared to the associated mean population level when all of the parameters are set at their mean value. Each parameter was deviated by $\pm 10 \%$ to determine the effect of the parameter on the model (Essington 2003; Table 1). If the parameter causes a $10 \%$ deviation in the results of the simulation model, then the parameter is linearly related. If the parameter causes less than a $10 \%$ deviation in the results of the simulation model, then the parameter is an insensitive parameter. If the parameter causes greater than a $10 \%$ deviation in the results of the simulation model, then the parameter is a highly sensitive parameter. The model was run 1,000 times per sensitivity analysis for 200 years. For each sensitivity analysis, the initial population 
abundance was set at 4,757 individuals, which was the average age- $3+$ abundance for Escanaba Lake during 1980-2001. The exploitation rate was set at 35\% for angling and $0 \%$ for spearing for one set of simulations, and $0 \%$ for angling and $35 \%$ for spearing for a second set of simulations. The average adult population size of fish age 3 and older from year 51 to year 200 was recorded for each simulation.

Sustainability of the $35 \%$ exploitation rate was evaluated over a range of initial abundances $\left(N_{i j}\right)$ and total instantaneous fishing mortality rates $\left(F_{i}\right)$. Initial abundances tested in the model varied with lake size through a linear model with $95 \%$ prediction intervals (Nate et al. 2000). Abundances for five different lake sizes were tested, including 128 walleyes in a 100 -acre lake, 592 walleyes in a 500-acre lake, 1,139 walleyes in a 1,000-acre lake, 5,158 walleyes in a 5,000-acre lake, and 9,844 walleyes in a 10,000-acre lake. The lower $95 \%$ prediction limits for the abundance of each of those lakes sizes was tested, because lakes with varying size should have varying levels of extinction risk and time to extinction. Simulations were run 1,000 times for 200 years for each adult population size at varying levels of angler exploitation. Sustainability was also tested for three types of fisheries, including unregulated angling (no size or bag limits), angling with a 15 in minimum size limit, and spearing.

The probability of extinction, probability of decline, time to extinction, and average age-3+ abundance were each examined as indices of sustainability for each population and lake size tested. Probability of extinction was the proportion of 1,000 simulations that extinction occurred. Probability of decline was the proportion of 1,000 simulations that the average abundance from year 51 to 200 was below the initial abundance. The probability of decline that was deemed sustainable was at the 
exploitation rate that caused 1 in 40 or less of the simulations to result in an average abundance less than the initial abundance. Time to extinction was the median time to extinction for the 1,000 simulations. The average abundance was the median average abundance for the 1,000 simulations.

\section{Results}

Walleye recruitment varied with size of the reproductive stock:

$$
N_{i, j=0}=34.903\left(N_{i j} M_{j}\right) e^{-0.0014^{*}\left(4757 / N_{i j}\right) N_{i j} M_{j}} e^{0.5}
$$

where 34.903 was the number of age 0 walleyes produced per adult female walleye at low female abundance, $0.0014 *\left(4757 / N_{i j}\right)$ was the instantaneous rate at which the recruitment rate declined as adult walleye abundance increased, and multiplicative process error was 0.5 .

Relative selectivity of the spearing fishery had a delayed age of entry into the harvestable population compared to the unregulated angling fishery and the angling fishery with a 15 in minimum length limit. For an unregulated angling fishery, relative selectivity started to rise above $0 \%$ at age 0.5 , reached $50 \%$ at age 2.5 , and reached $100 \%$ at age 5 (Figure 9). For an angling fishery with a 15 in minimum length limit, relative selectivity started to rise above $0 \%$ at age 1.0 , reached $50 \%$ at age 3.5 , and reached $100 \%$ at age 6 (Figure 9). For a spearing fishery, relative selectivity started to rise above $0 \%$ at age 0 , reached $50 \%$ at age 5 , and reached $100 \%$ at age 15 (Figure 9 ).

In the sensitivity analysis, no parameters for the model were linearly or strongly related to the results, because none of the simulations induced deviations in the results from the baseline greater than $10 \%$. For the angling sensitivity analysis, $\pm 10 \%$ deviations 
in $j_{50}$ of the angling selectivity curve, the slope of the natural mortality regression line, $\alpha$ from the stock recruitment curve, and the $-10 \%$ deviation in $j_{50}$ of the age at $50 \%$ maturity all induced greater than a $5 \%$ difference in mean adult abundance (Table 2). For the spearing sensitivity analysis, $\pm 10 \%$ deviations of $\beta$ from the stock recruitment curve and the $-10 \%$ deviation in $j_{50}$ of the age at $50 \%$ maturity induced greater than a $5 \%$ difference in mean adult abundance (Table 3).

For an unregulated angling fishery (no bag or length limits), a 35\% exploitation rate induced a zero probability of extinction and zero probability of decline. The probability of extinction started to rise above $0 \%$ at angler exploitation rates of $56-61 \%$ for initial population sizes of $128,592,1,139,5,158$, and 9,844 adult walleyes (lake sizes of $100,500,1,000,5,000$, and 10,000 acres, respectively), reached $50 \%$ at angler exploitation rates of $62-66 \%$, and reached $100 \%$ at angler exploitation rates of $65-70 \%$ (Figure 10). The probability of decline started to rise above $0 \%$ at the angler exploitation rate of $47 \%$ for all initial population sizes, reached $50 \%$ at the angler exploitation rate of $54 \%$, and reached $100 \%$ at the angler exploitation rate of $62 \%$ (Figure 11 ). As the angling exploitation rate increased, the average adult population size decreased (Figure 12), and the time to extinction decreased (Figure 13). As lake size increased, time to extinction increased for a constant angling exploitation rate, and as initial population size increased, time to extinction increased for a constant angling exploitation rate (Figure 14).

For an angling fishery with a 15 in minimum length limit, a 35\% exploitation rate induced a zero probability of decline and zero probability of extinction. The probability of extinction started to rise above $0 \%$ at angler exploitation rates of $73-76 \%$ for initial population sizes of $128,592,1,139,5,158$, and 9,844 adult walleyes (lake sizes of 100 , 
$500,1,000,5,000$, and 10,000 acres, respectively), reached $50 \%$ at angler exploitation rates of $75-80 \%$, and reached $100 \%$ at angler exploitation rates of $80-85 \%$ (Figure 10 ). The probability of decline started to rise above $0 \%$ at the angler exploitation rate of $60 \%$ for all initial population sizes, reached $50 \%$ at the angler exploitation rate of $71 \%$, and reached $100 \%$ at the angler exploitation rate of $75 \%$ (Figure 11). As the angling exploitation rate increased, the average adult population size decreased (Figure 15), and the time to extinction decreased (Figure 16). As lake size increased, time to extinction increased for a constant angling exploitation rate, and as initial population size increased, time to extinction increased for a constant angling exploitation rate (Figure 14).

For a spearing fishery, a 35\% exploitation rate induced a zero probability of extinction and zero probability of decline. The probability of extinction started to rise above $0 \%$ at spearing exploitation rates of $75-80 \%$ for initial population sizes of 128,592 , $1,139,5,158$, and 9,844 adult walleyes (lake sizes of 100,500, 1,000, 5,000, and 10,000 acres, respectively), reached $50 \%$ at spearing exploitation rates of $81-84 \%$, and reached $100 \%$ at spearing exploitation rates of $85-90 \%$ (Figure 10). The probability of decline started to rise above $0 \%$ at the spearing exploitation rate of $60 \%$ for all initial population sizes, reached $50 \%$ at the spearing exploitation rate of $71 \%$, and reached $100 \%$ at the spearing exploitation rate of $75 \%$ (Figure 11). As the spearing exploitation rate increased, the average adult population size decreased (Figure 17), and the time to extinction decreased (Figure 18). As lake size increased, the time to extinction increased for a constant spearing exploitation rate, and as initial population size increased, time to extinction increased for a constant spearing exploitation rate (Figure 14). 


\section{Discussion}

I found that a $35 \%$ total annual exploitation rate induced zero risk of extinction for both angling and spearing fisheries over all lake sizes and starting population sizes. This finding supports the current walleye population management in northern Wisconsin where a $35 \%$ total annual exploitation rate has been utilized to avoid overexploitation of populations in individual lakes (Staggs et al. 1990). A zero risk of extinction ensures that the state of Wisconsin is currently meeting the primary objective of walleye population management, which is to allow both tribal spearing and angling harvest, yet still maintain naturally reproducing walleye populations (BIA 1991).

I found that walleye populations sustained a zero extinction risk at exploitation rates of $56-61 \%$ for unregulated angling fisheries, $73-76 \%$ for angling fisheries with a 15-in minimum length limit, and $75-80 \%$ for spearing fisheries, which were similar and higher than exploitation rates for fisheries for which models were used to quantify the harvest rate that would lead to the collapse of a stock. For example, my findings were similar to exploitation rates of $67-72 \%$ for Pacific hake Merluccius productus in the Pacific Ocean where $\mathrm{F}_{\mathrm{CRIT}}$ was determined as the maximum sustainable fishing mortality rate to avoid stock collapse (Brodziak 2002). Pacific hake are similar to walleyes in that they mature at a young age, around 3 or 4, and are fairly short-lived, fast growing species. My findings were higher than exploitation rates of $14 \%$ for Dover sole Microstomus pacificus, $8 \%$ for lingcod Ophiodon elongates, 5\% for sablefish Anoplopoma fimbria, $8 \%$ for widow rockfish Sebastes entomelas in the Pacific Ocean where $F_{\text {CRIT }}$ was determined as the maximum sustainable fishing mortality rate to avoid stock collapse (Brodziak 2002), and for the porbeagle Lamna nasus in the Atlantic Ocean where $8 \%$ was the 
exploitation rate where the population could still replace itself and avoid stock collapse (Campana et al. 2002). All of these species mature later and are larger, longer-lived species than the walleye, so take longer to replace themselves.

I found that a $35 \%$ total annual exploitation rate induced zero risk of decline for both angling and spearing fisheries over all lake sizes and starting population sizes. For example, I found that unregulated walleye populations could withstand exploitation rates of $47 \%$, which is similar to exploitation rates of $40-60 \%$ withstood by sauger Sander canadense in the Tennessee River of Alabama, where no size limits exist and the daily bag limit of 15 fish exists (Maceina et al. 1998). Similarly, I found that walleye populations with a 15 in minimum length limit could withstand exploitation rates of $60 \%$, which is higher than exploitation rates currently found in Wisconsin, where the mean angling exploitation rate was $8.38 \%$ and the maximum angling exploitation rate was $62 \%$ (Beard et al. 2003b). Last, I found that walleye populations subjected to spearing exploitation could withstand a $60 \%$ exploitation rate, which is higher than exploitation rates currently found in Wisconsin where the mean spearing exploitation rate was $3.45 \%$ and the maximum spearing exploitation rate was $13.5 \%$ (Beard et al. 2003b).

I found that delaying the age at entry of fish to the harvestable population reduced the risk of overexploitation, which is similar to findings of other studies where delaying the age of entry into a fishery reduced the risk of overexploitation in simulation models of little skate Leucoraja erinacea, winter skate Leucoraja ocellata, and barndoor skate Dipturus laevis in the western Atlantic (Frisk et al. 2002), bull trout Salvelinus confluentus in Alberta, Canada (Post et al. 2003), and striped bass Morone saxatilis in the Santee-Cooper system of South Carolina (Bulak et al. 1995). The spearing fishery and 
the angling fishery with a 15 in minimum length limit resulted in a lower risk of overexploitation to the walleye population because the age of entry into the fishery was delayed compared to the unregulated angling fishery. This delay of entry into the fishery allows fish to become mature and to spawn before being harvested, thereby replacing themselves in the population (Frisk et al. 2002).

I found that larger populations had lower risks of extinction and decline, which is similar to other studies where larger populations had a lower risk of extinction and decline than smaller populations because of a decreased influence of demographic and environmental stochasticity (Ricklefs 1983; Pimm et al. 1988; Tracy and George 1992; Dulvy et al. 2004). I found that the initial abundance of the population was inversely related to the risks of decline and extinction, which is similar to studies of Atlantic salmon in the Gulf of Maine, in which the smallest sub-populations had the highest risks of extinction (Legault 2005). I found that smaller initial populations had shorter time to extinction, and increased risk of extinction than larger populations, which is similar to findings for the Florida manatee Trichechus manatus latirostris in the Atlantic Ocean and the Gulf of Mexico (Marmontel et al. 1997).

\section{Management Implications}

My findings suggest that walleye populations could be sustained in northern Wisconsin lakes even if total annual exploitation rates of walleye fisheries were increased to $47 \%$ for unregulated angling fisheries, $60 \%$ for angling fisheries with a 15 in minimum length limit, and $60 \%$ for spearing fisheries. However, before implementing an increased annual exploitation rate, my modeling results should be evaluated experimentally. For example, to evaluate the sustainability of walleye populations in lakes that are subjected 
to spearing fisheries and angling fisheries with a 15 -in minimum length limit, three sets of lakes could be randomly selected for management under exploitation rates of $35 \%$ (current policy), 60\% (higher sustainable policy), and 75\% (non-sustainable policy). Within each treatment group, spearing quotas and angling creel limits could be set using current methods, though the findings would be clearer if the allocation between spearing and angling was constant for all lakes in the experiment. The number of lakes in each treatment group should be large enough to quantify the natural variation within each group (e.g. 30 lakes per treatment group), but would obviously be limited by available fiscal and human resources.

My simulation model could be strengthened by adding density-dependent growth, to quantify temporal changes in population abundance and related changes in the age at which fish become vulnerable to harvest in each type of fishery. For example, reduced population density would likely lead to faster growth, earlier maturity, and thus, earlier entry to harvest by spearing. To account for such density-dependent changes in growth and selectivity, a Von Bertalanffy length-age sub-model could be added to the simulation model that describes the mean length of fish in each age class $\left(L_{t}=L_{\infty}\left(1-e^{-K\left(t-t_{0}\right)}\right)\right)$. Next, to account for density-dependent changes in population growth rate, parameters of the length-age sub-model could be related to simulated population densities so that the growth rate $(K)$ is directly related to population density and the asymptotic size $\left(L_{\infty}\right)$ is inversely related to population density. Last, to convert changes in growth to changes in fishery selectivity, the mean size of fish in each age class could be related to parameters of the selectivity sub-model $\left(j_{50}\right.$ and $\left.j_{95}\right)$ to change the shape of the selectivity curve with changes in growth (i.e. selectivity shifts to younger age at entry when growth increases). 
Table 1. Parameters tested for their sensitivity to a change in the parameter value by $+10 \%$ and $-10 \%$.

\section{Parameter Parameter Description}

Baseline The baseline run for the sensitivity analysis.

Spearing $j 50$ The age at $50 \%$ selectivity for the spearing selectivity curve.

Spearing $j 95$ The age at $95 \%$ selectivity for the spearing selectivity curve.

Angling $j 50 \quad$ The age at $50 \%$ selectivity for the angling selectivity curve.

Angling $j 95$ The age at $95 \%$ selectivity for the angling selectivity curve.

M-slope $\quad$ The slope of the regression line for the natural mortality (M).

M-intercept The intercept of the regression line for the natural mortality (M).

M-error $\quad$ The error term of the regression line for the natural mortality (M).

S-R alpha The alpha term of the Ricker stock-recruitment curve.

S-R beta The beta term of the Ricker stock-recruitment curve.

S-R error The error term of the Ricker stock-recruitment curve.

Maturity $j 50 \quad$ The age at $50 \%$ maturity for the maturity curves.

Maturity stdev The standard deviation of the age at $50 \%$ maturity for the maturity curves. 
Table 2. Parameter tested, deviation tested, mean average adult abundance, the upper and lower $95 \%$ of the average adult abundance, and the percent difference between the baseline mean and the mean for each parameter deviation for an angling only fishery where the model was run 1000 simulations and 200 years.

\begin{tabular}{lrrrrr}
\hline Parameter & Deviation & Mean & Lower 95\% & Upper $95 \%$ & $\begin{array}{r}\text { Mean \% } \\
\text { Difference }\end{array}$ \\
\hline Baseline & - & 4,658 & 4,408 & 4,910 & - \\
Spearing $j 50$ & $-10 \%$ & 4,658 & 4,414 & 4,938 & 0.00 \\
Spearing $j 50$ & $+10 \%$ & 4,657 & 4,426 & 4,910 & -0.02 \\
Spearing $j 95$ & $-10 \%$ & 4,670 & 4,397 & 4,912 & 0.26 \\
Spearing $j 95$ & $+10 \%$ & 4,655 & 4,426 & 4,911 & -0.06 \\
Angling $j 50$ & $-10 \%$ & 4,400 & 4,159 & 4,641 & -5.54 \\
Angling $j 50$ & $+10 \%$ & 4,938 & 4,662 & 5,176 & 6.00 \\
Angling $j 95$ & $-10 \%$ & 4,674 & 4,402 & 4,913 & 0.33 \\
Angling $j 95$ & $+10 \%$ & 4,644 & 4,408 & 4,905 & -0.31 \\
M-slope & $-10 \%$ & 4,918 & 4,672 & 5,193 & 5.58 \\
M-slope & $+10 \%$ & 4,423 & 4,185 & 4,665 & -5.06 \\
M-intercept & $-10 \%$ & 4,761 & 4,499 & 5,010 & 2.21 \\
M-intercept & $+10 \%$ & 4,566 & 4,305 & 4,812 & -1.98 \\
M-error & $-10 \%$ & 4,668 & 4,417 & 4,929 & 0.21 \\
M-error & $+10 \%$ & 4,645 & 4,393 & 4,904 & -0.29 \\
S-R alpha & $-10 \%$ & 4,392 & 4,135 & 4,632 & -5.71 \\
S-R alpha & $+10 \%$ & 4,917 & 4,640 & 5,200 & 5.56 \\
S-R beta & $-10 \%$ & 4,886 & 4,607 & 5,153 & 4.89 \\
S-R beta & $+10 \%$ & 4,448 & 4,212 & 4,697 & -4.51 \\
S-R error & $-10 \%$ & 4,608 & 4,369 & 4,847 & -1.07 \\
S-R error & $+10 \%$ & 4,726 & 4,455 & 5,004 & 1.46 \\
Maturity $j 50$ & $-10 \%$ & 4,693 & 4,468 & 4,929 & 0.75 \\
Maturity $j 50$ & $+10 \%$ & 4,399 & 4,114 & 4,668 & -5.56 \\
Maturity SD & $-10 \%$ & 4,680 & 4,416 & 4,929 & 0.47 \\
Maturity SD & $+10 \%$ & 4,641 & 4,385 & 4,890 & -0.38 \\
\hline & & & & &
\end{tabular}


Table 3. Parameter tested, deviation tested, mean average adult abundance, the upper and lower $95 \%$ of the average adult abundance, and the percent difference between the baseline mean and the mean for each parameter deviation for a spearing only fishery where the model was run 1000 simulations and 200 years.

\begin{tabular}{lrrrrr}
\hline Parameter & Deviation & Mean & Lower 95\% & Upper 95\% & $\begin{array}{r}\text { Mean } \% \\
\text { Difference }\end{array}$ \\
\hline Baseline & - & 6,317 & 6,065 & 6,576 & - \\
Spearing $j 50$ & $-10 \%$ & 6,079 & 5,839 & 6,334 & -3.77 \\
Spearing $j 50$ & $+10 \%$ & 6,489 & 6,249 & 6,754 & 2.72 \\
Spearing $j 95$ & $-10 \%$ & 6,469 & 6,222 & 6,730 & 2.41 \\
Spearing $j 95$ & $+10 \%$ & 6,181 & 5,923 & 6,424 & -2.15 \\
Angling $j 50$ & $-10 \%$ & 6,315 & 6,082 & 6,575 & -0.03 \\
Angling $j 50$ & $+10 \%$ & 6,323 & 6,082 & 6,566 & 0.09 \\
Angling $j 95$ & $-10 \%$ & 6,324 & 6,084 & 6,581 & 0.11 \\
Angling $j 95$ & $+10 \%$ & 6,321 & 6,070 & 6,575 & 0.06 \\
M-slope & $-10 \%$ & 6,601 & 6,332 & 6,867 & 4.50 \\
M-slope & $+10 \%$ & 6,062 & 5,834 & 6,298 & -4.04 \\
M-intercept & $-10 \%$ & 6,397 & 6,155 & 6,657 & 1.27 \\
M-intercept & $+10 \%$ & 6,245 & 5,992 & 6,497 & -1.14 \\
M-error & $-10 \%$ & 6,333 & 6,078 & 6,577 & 0.25 \\
M-error & $+10 \%$ & 6,317 & 6,064 & 6,586 & 0.00 \\
S-R alpha & $-10 \%$ & 6,070 & 5,829 & 6,297 & -3.91 \\
S-R alpha & $+10 \%$ & 6,560 & 6,317 & 6,821 & 3.85 \\
S-R beta & $-10 \%$ & 6,692 & 6,447 & 6,967 & 5.94 \\
S-R beta & $+10 \%$ & 5,977 & 5,746 & 6,212 & -5.38 \\
S-R error & $-10 \%$ & 6,266 & 6,049 & 6,490 & -0.81 \\
S-R error & $+10 \%$ & 6,375 & 6,117 & 6,652 & 0.92 \\
Maturity $j 50$ & $-10 \%$ & 5,965 & 5,743 & 6,206 & -5.57 \\
Maturity $j 50$ & $+10 \%$ & 6,508 & 6,241 & 6,801 & 3.02 \\
Maturity SD & $-10 \%$ & 6,342 & 6,083 & 6,573 & 0.40 \\
Maturity SD & $+10 \%$ & 6,303 & 6,059 & 6,550 & -0.22 \\
\hline & & & & &
\end{tabular}




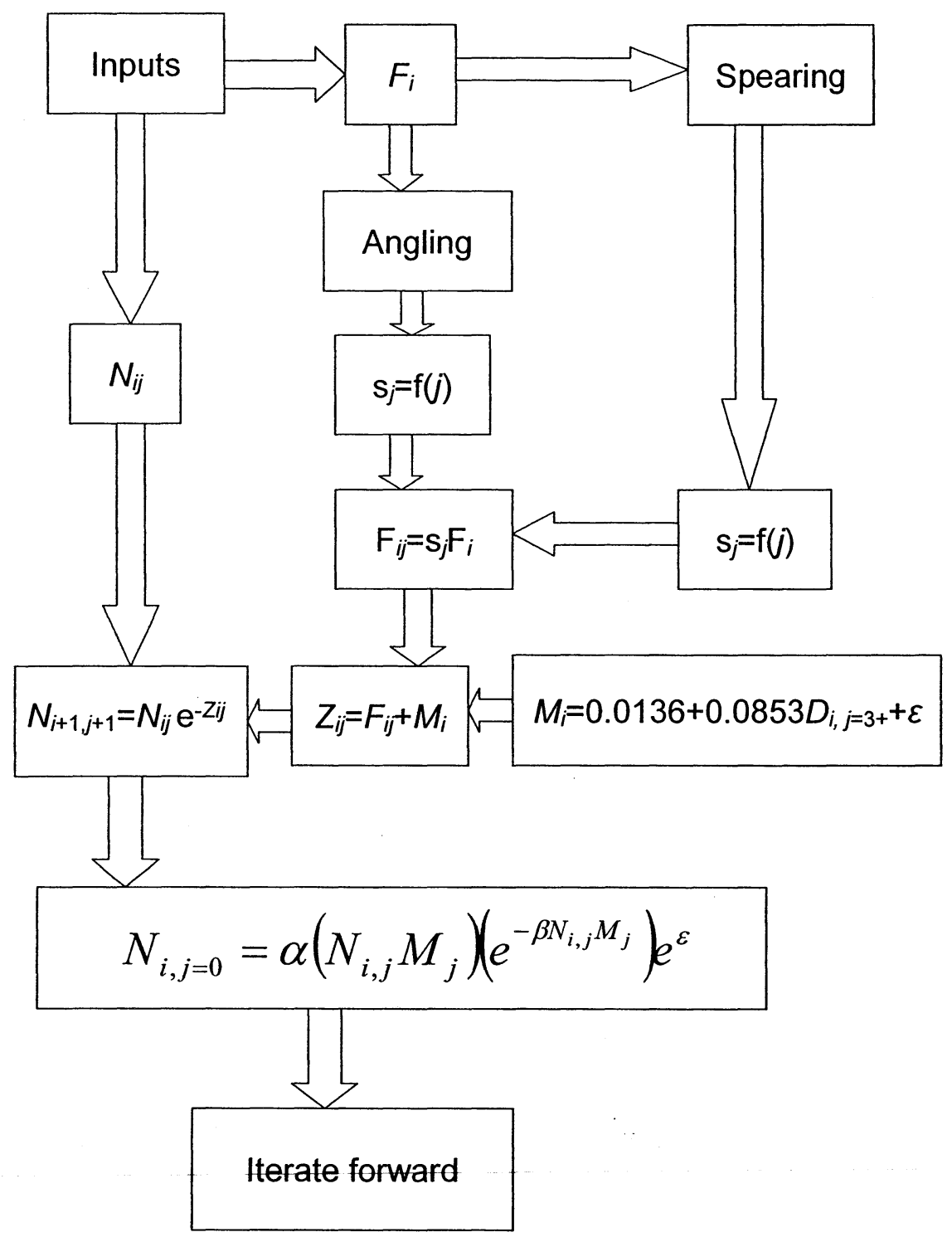

Figure 8. A schematic diagram of the simulation model where $i$ is year and $j$ is age and the inputs are the total instantaneous fishing mortality rate $\left(F_{i}\right)$ for each fishery in year $i$ and the initial abundance $\left(N_{i j}\right)$ in year $i$ for age $j$. 

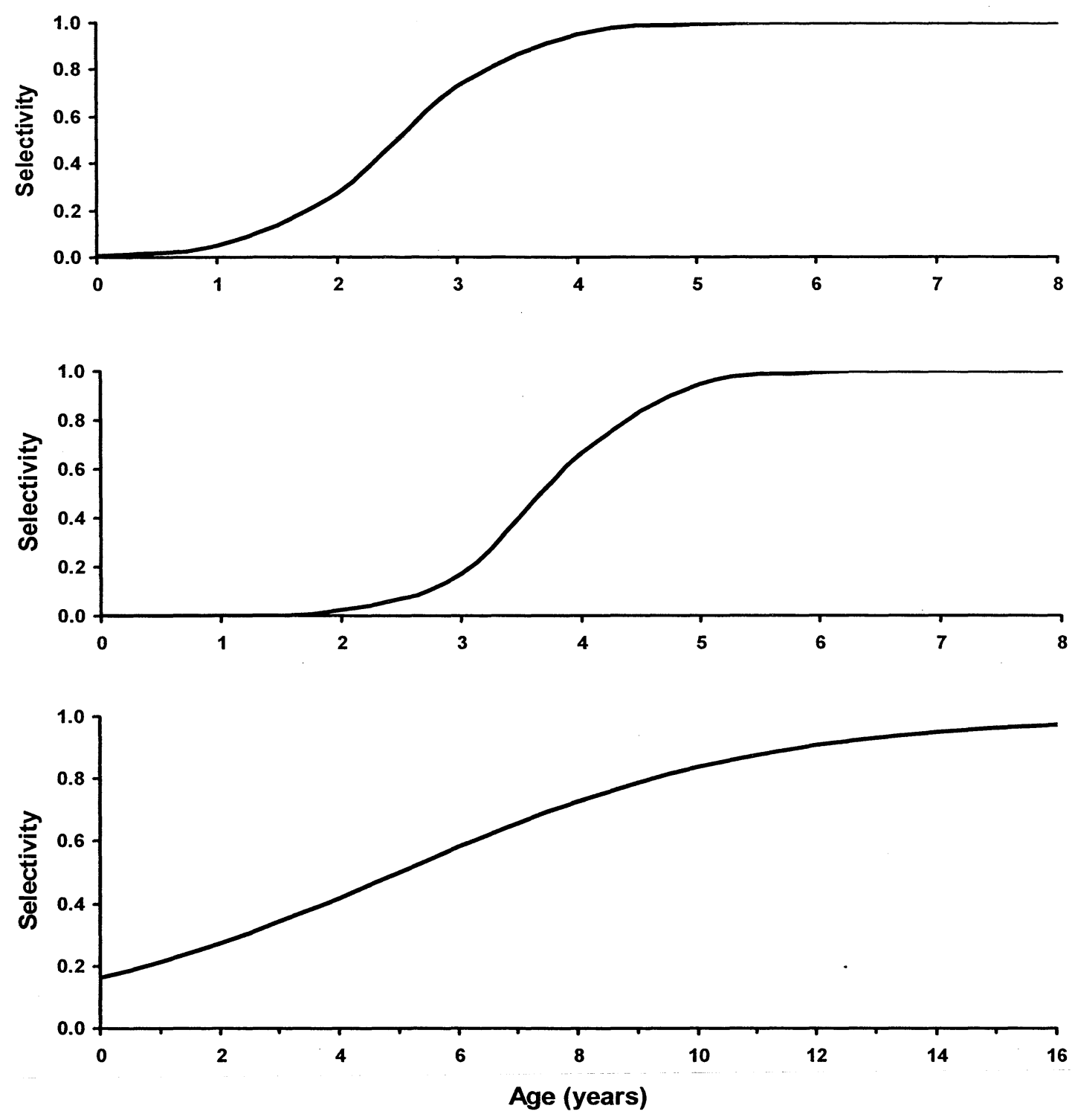

Figure 9. Selectivity curves for an unregulated angling fishery (upper panel), an angling fishery with a 15 in minimum length limit (middle panel), and a spearing fishery (lower panel) in Wisconsin's ceded territory. 

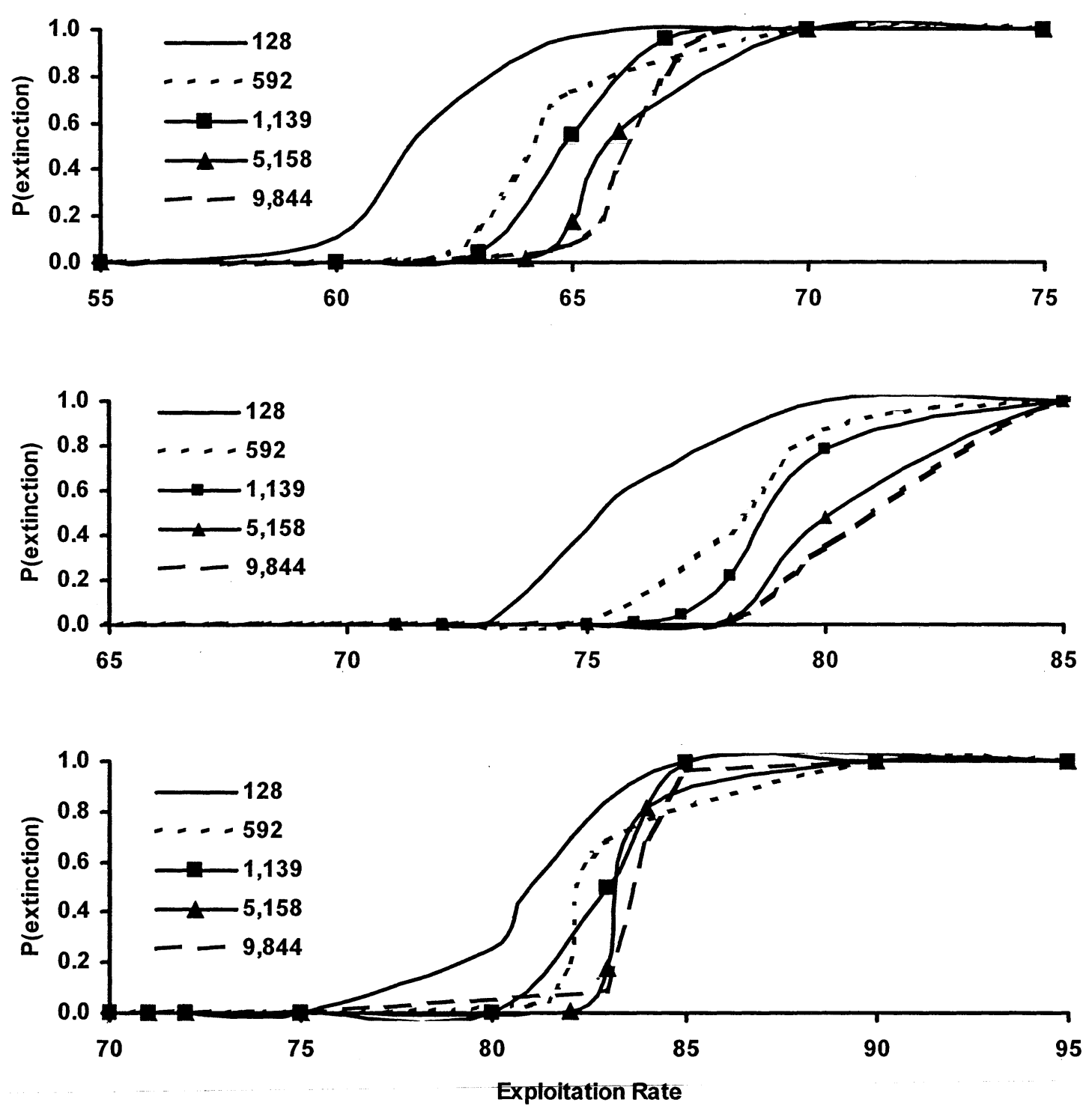

Figure 10. The probability of extinction versus exploitation rate for initial population sizes of 128 adult walleyes in a 100-acre lake, 592 adult walleyes in a 500 -acre lake, 1,139 adult walleyes in a 1,000-acre lake, 5,158 adult walleyes in a 5,000-acre lake, and 9,844 adult walleyes in a 10,000-acre lake with unregulated angling exploitation (upper panel), angling exploitation with a 15 in minimum length limit (middle panel), and spearing exploitation (lower panel). Simulations were run 1,000 times for 200 years. 

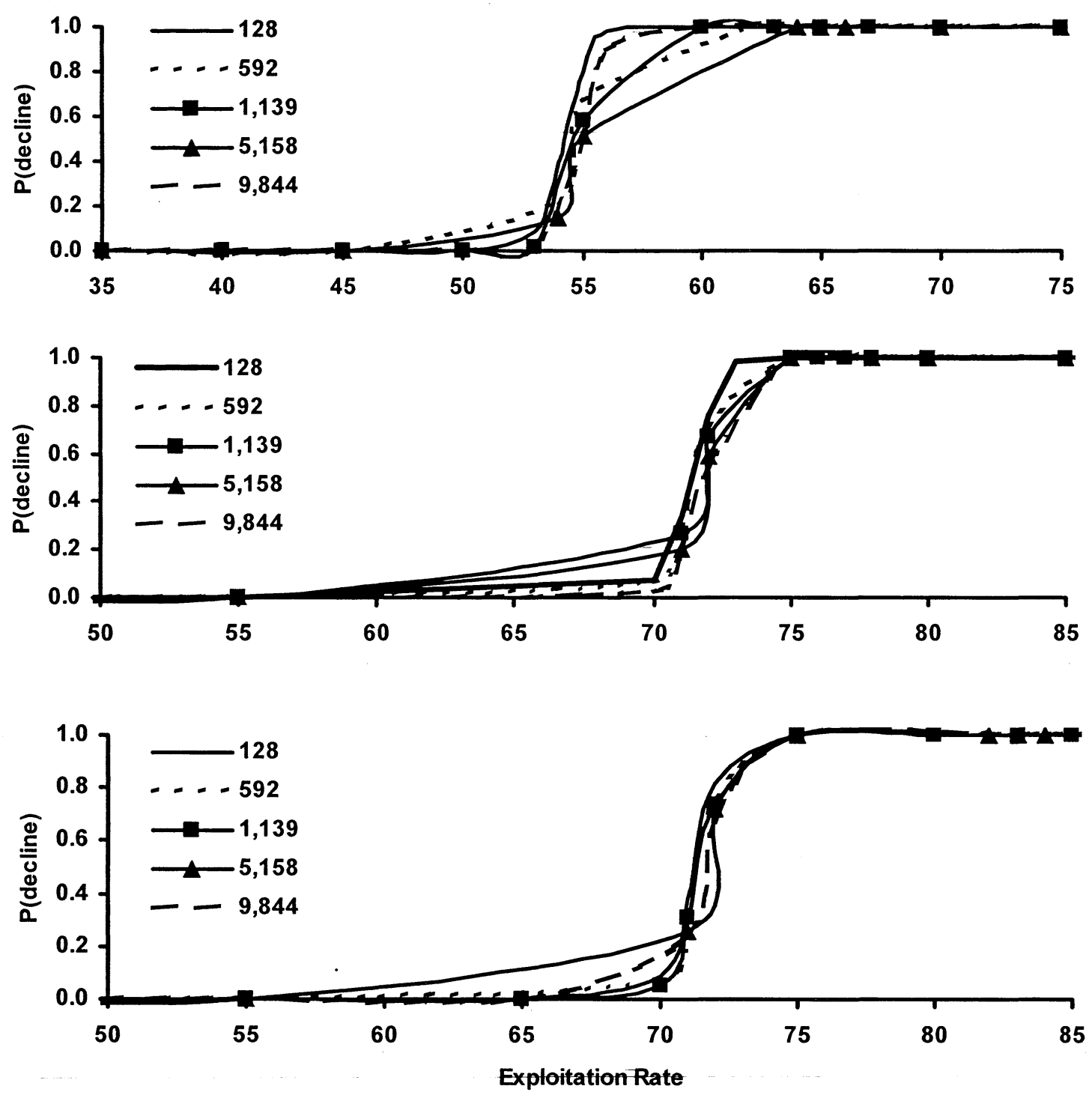

Figure 11. The probability of decline versus exploitation rate for initial population sizes of 128 adult walleyes in a 100 -acre lake, 592 adult walleyes in a 500 -acre lake, 1,139 adult walleyes in a 1,000-acre lake, 5,158 adult walleyes in a 5,000-acre lake, and 9,844 adult walleyes in a 10,000-acre lake with unregulated angling exploitation (upper panel), angling exploitation with a 15 in minimum length limit (middle panel), and spearing exploitation (lower panel). Simulations were run 1,000 times for 200 years. 

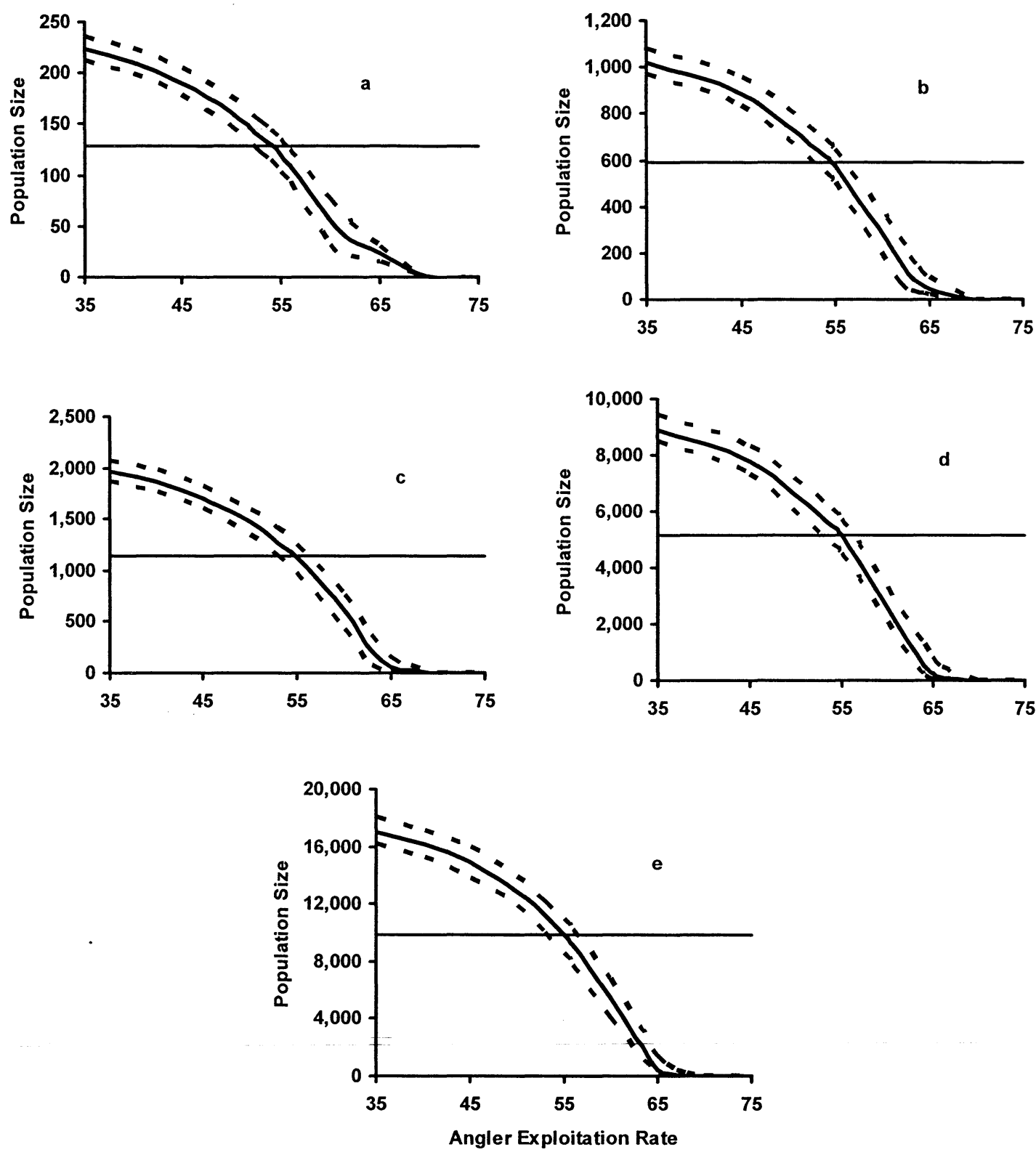

Figure 12 . The average adult abundance $\pm 95 \%$ confidence intervals versus exploitation rate for initial population sizes of 128 adult walleyes in a 100-acre lake (panel a), 592 adult walleyes in a 500-acre lake (panel b), 1,139 adult walleyes in a 1,000-acre lake (panel c), 5,158 adult walleyes in a 5,000-acre lake (panel d), and 9,844 adult walleyes in a 10,000-acre lake (panel e) with unregulated angling exploitation. Simulations were run 1,000 times for 200 years. The horizontal line represents the initial population size. 

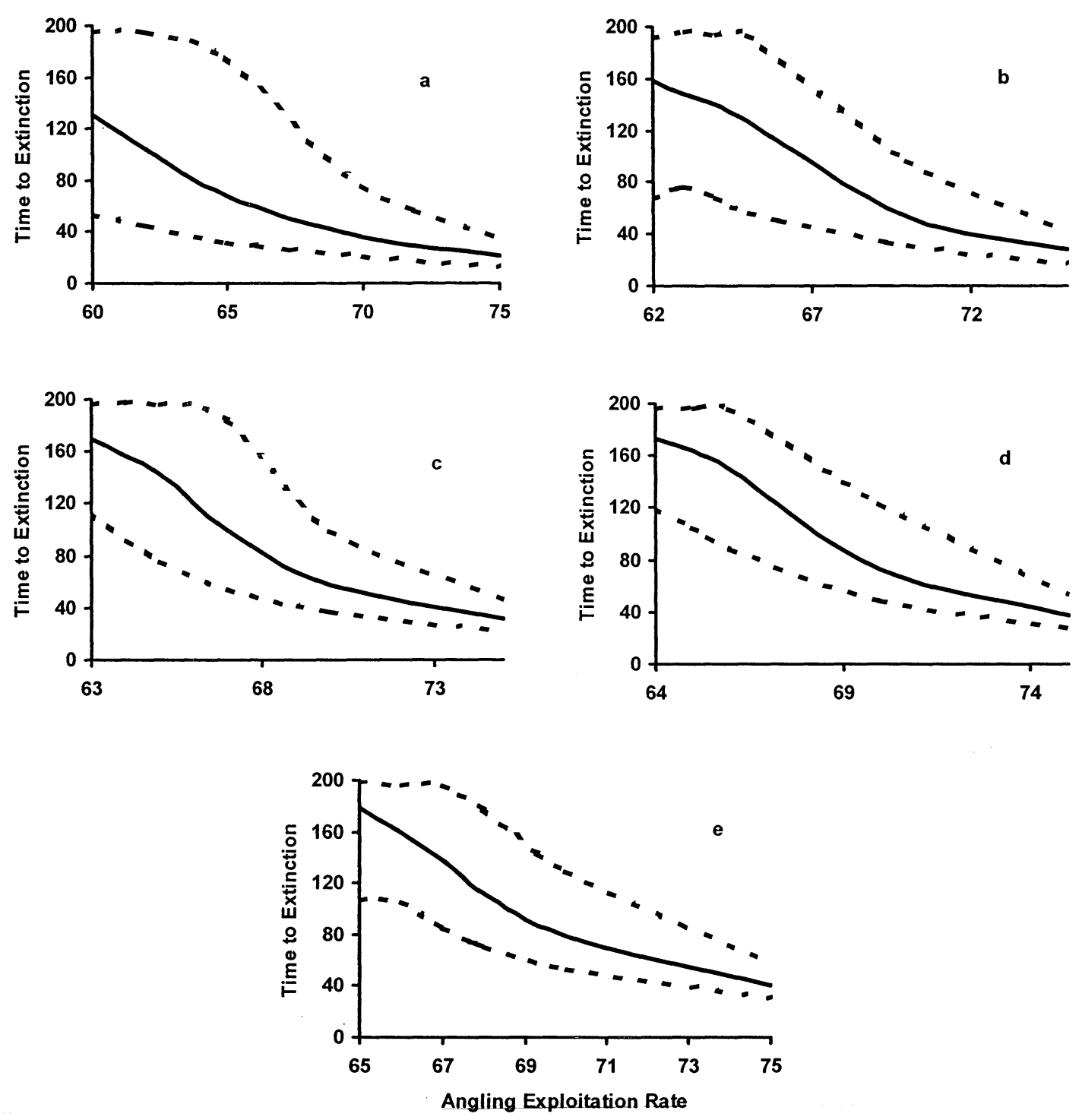

Figure 13. The time to extinction $\pm 95 \%$ confidence intervals versus angling exploitation rate for initial population sizes of 128 adult walleyes in a 100-acre lake (panel a), 592 adult walleyes in a 500-acre lake (panel b), 1,139 adult walleyes in a 1,000-acre lake (panel c), 5,158 adult walleyes in a 5,000-acre lake (panel d), and 9,844 adult walleyes in a 10,000-acre lake (panel e) with unregulated angling exploitation. Simulations were run 1,000 times for 200 years. 

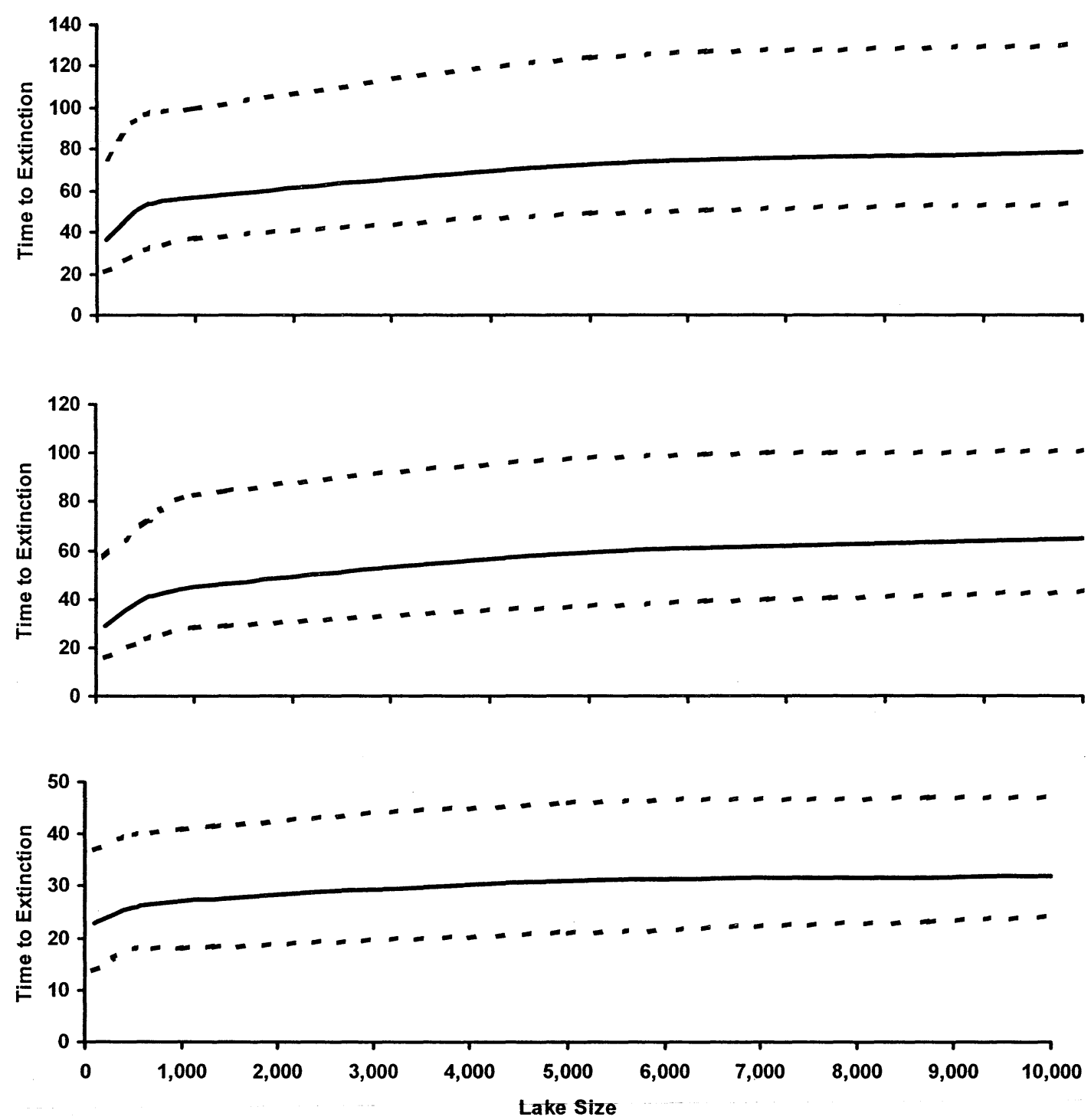

Figure 14. Initial population size versus time to extinction $\pm 95 \%$ confidence intervals for a constant exploitation rate for the unregulated angling fishery (upper panel), the angling fishery with a 15 in minimum length limit (middle panel), and the spearing fishery (lower panel). Simulations were run 1,000 times for 200 years. 

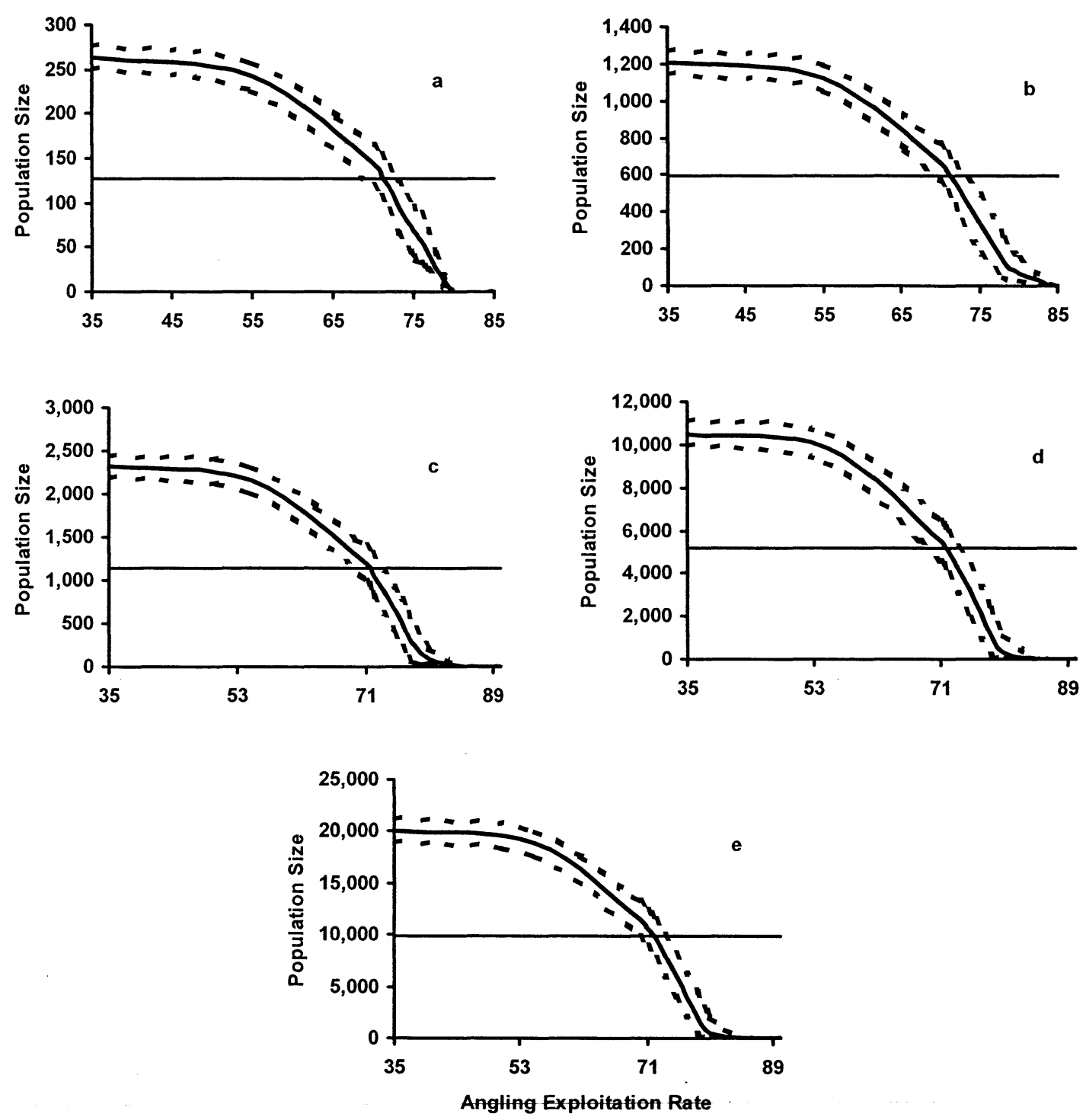

Figure 15 . The average adult abundance $\pm 95 \%$ confidence intervals versus exploitation rate for initial population sizes of 128 adult walleyes in a 100-acre lake (panel a), 592 adult walleyes in a 500-acre lake (panel b), 1,139 adult walleyes in a 1,000-acre lake (panel c), 5,158 adult walleyes in a 5,000-acre lake (panel d), and 9,844 adult walleyes in a 10,000-acre lake (panel e) with angling exploitation with a 15 in minimum length limit. Simulations were run 1,000 times for 200 years. The horizontal line represents the initial population size. 

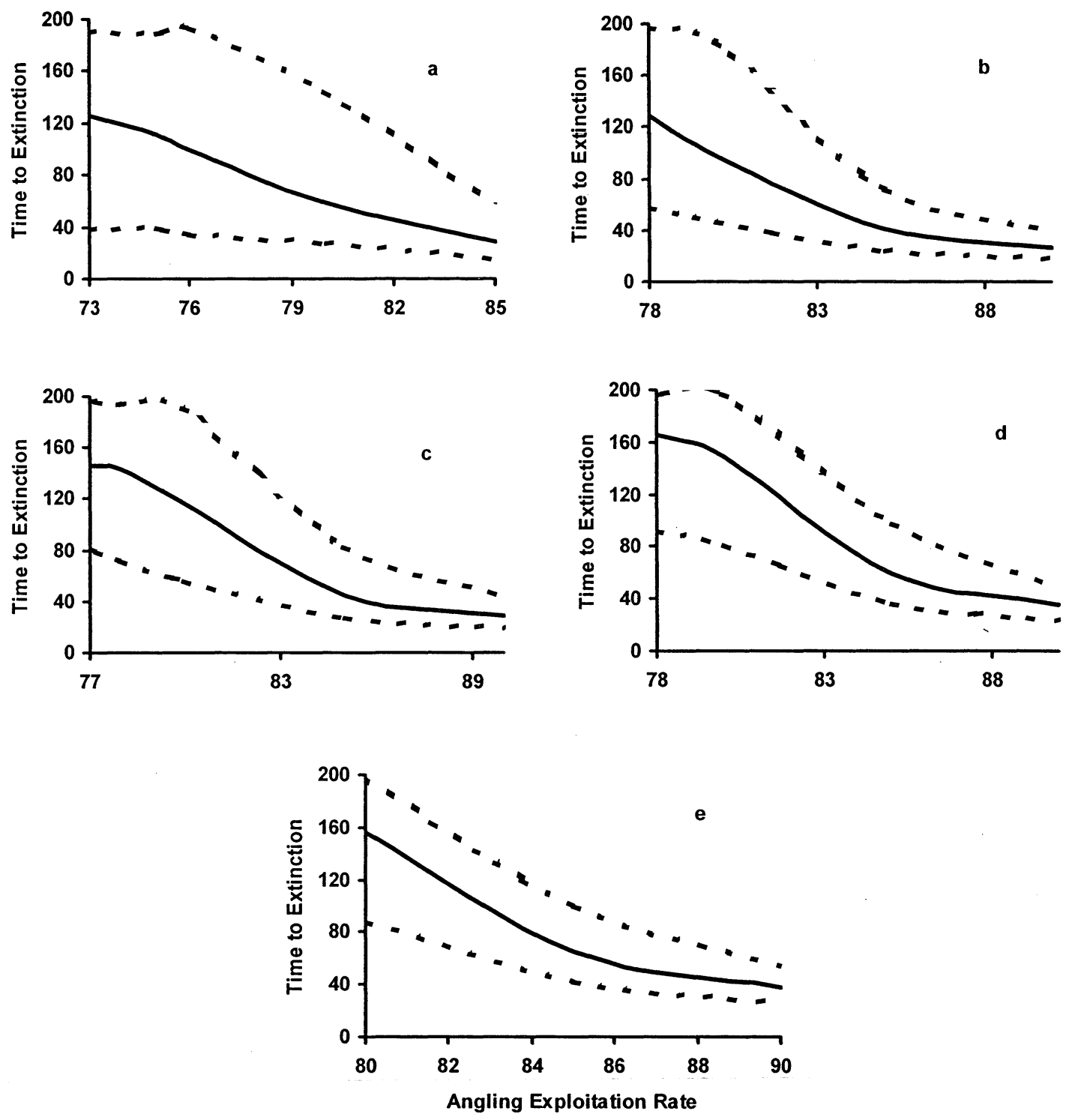

Figure 16. The time to extinction $\pm 95 \%$ confidence intervals versus exploitation rate for initial population sizes of 128 adult walleyes in a 100-acre lake (panel a), 592 adult walleyes in a 500-acre lake (panel b), 1,139 adult walleyes in a 1,000-acre lake (panel c), 5,158 adult walleyes in a 5,000-acre lake (panel d), and 9,844 adult walleyes in a 10,000acre lake (panel e) with angling exploitation with a 15 in minimum length limit. Simulations were run 1,000 times for 200 years. 

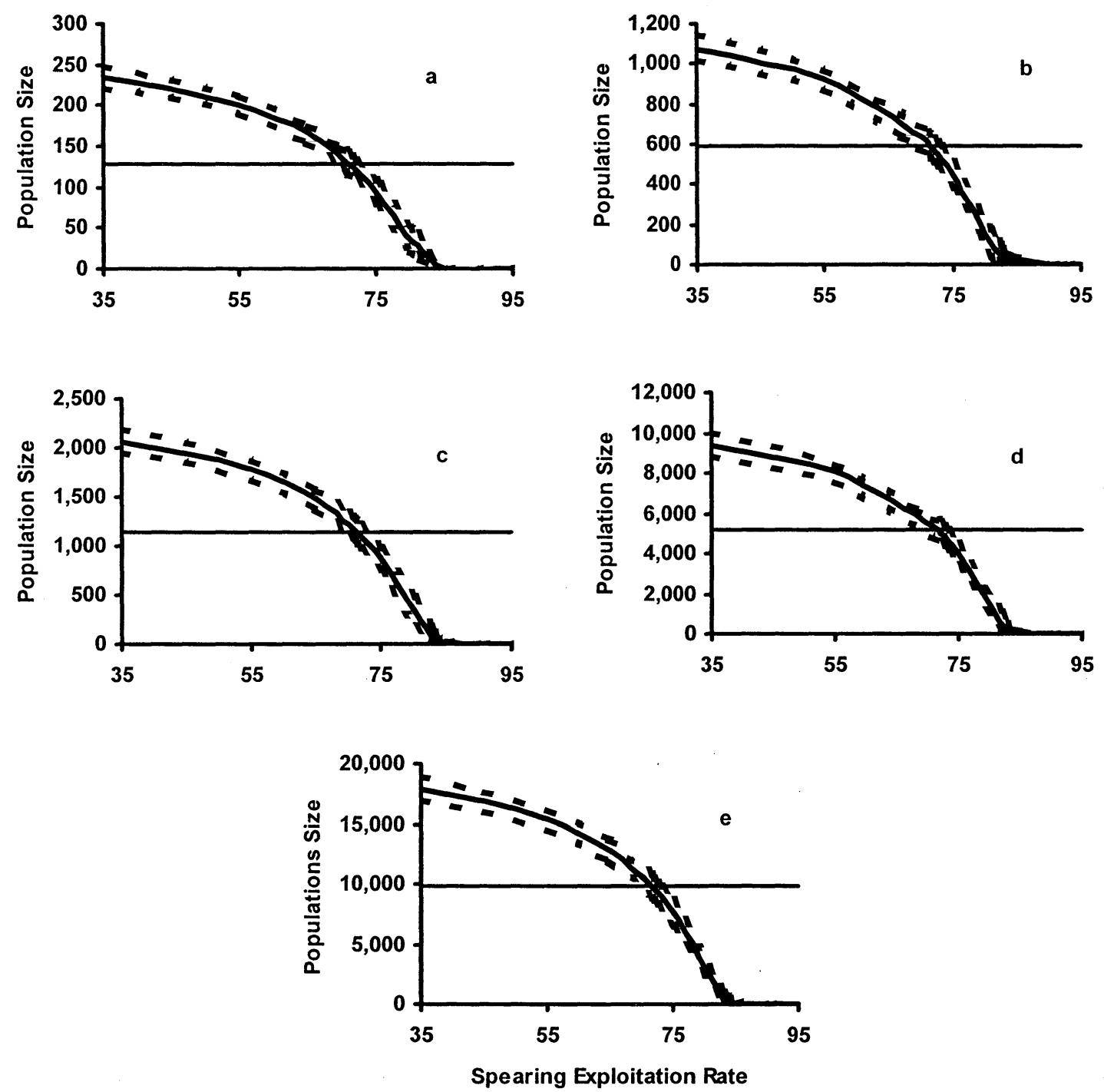

Figure 17. The average adult abundance $\pm 95 \%$ confidence intervals versus exploitation rate for initial population sizes of 128 adult walleyes in a 100-acre lake (panel a), 592 adult walleyes in a 500-acre lake (panel b), 1,139 adult walleyes in a 1,000-acre lake (panel c), 5,158 adult walleyes in a 5,000-acre lake (panel d), and 9,844 adult walleyes in a 10,000-acre lake (panel e) with spearing exploitation. Simulations were run 1,000 times for 200 years. The horizontal line represents the initial population size. 

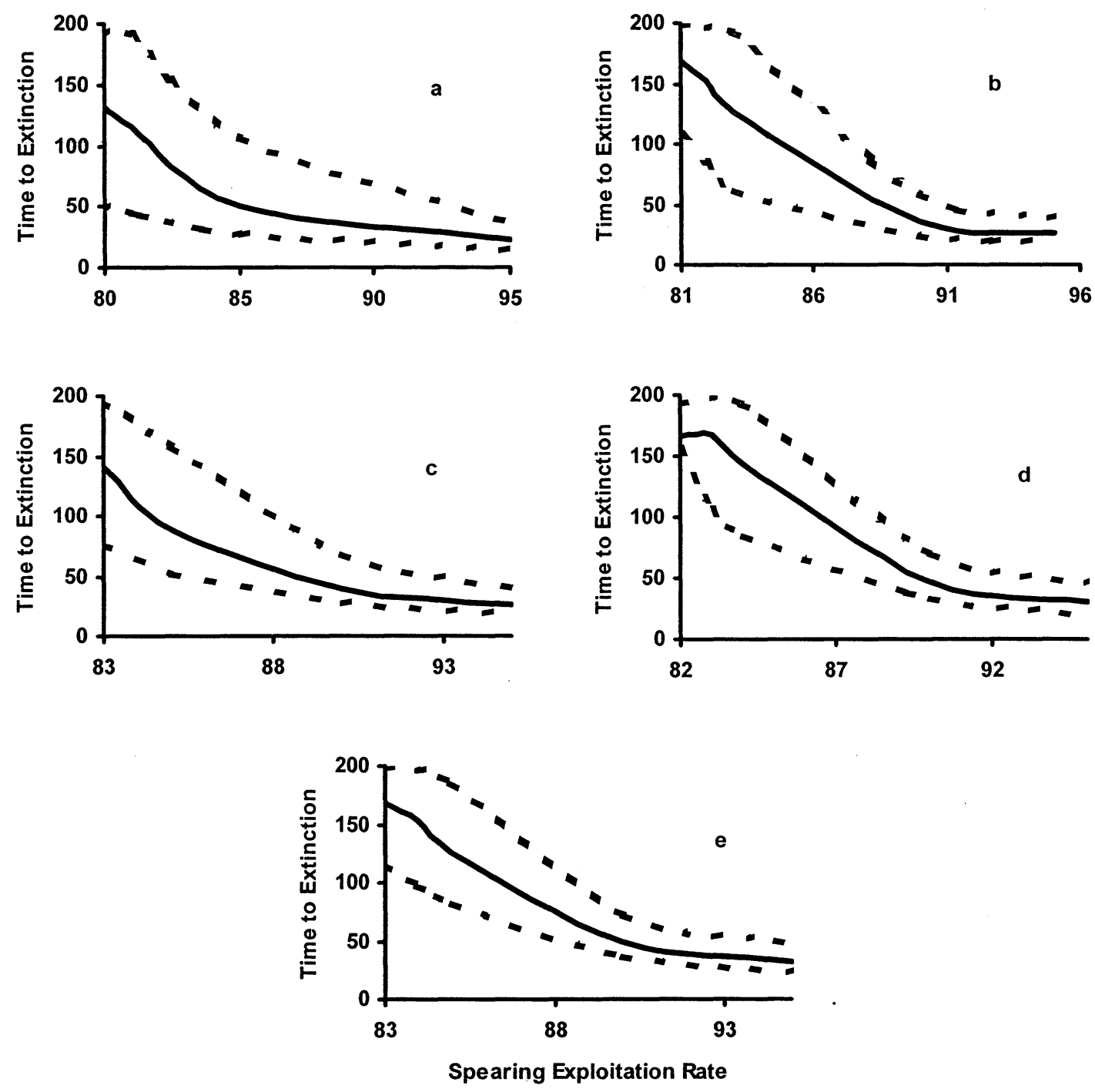

Figure 18 . The time to extinction $\pm 95 \%$ confidence intervals versus exploitation rate for initial population sizes of 128 adult walleyes in a 100-acre lake (panel a), 592 adult walleyes in a 500-acre lake (panel b), 1,139 adult walleyes in a 1,000-acre lake (panel c), 5,158 adult walleyes in a 5,000-acre lake (panel d), and 9,844 adult walleyes in a 10,000acre lake (panel e) with spearing exploitation. Simulations were run 1,000 times for 200 years. 


\section{CONCLUSIONS}

Yearly changes in age at maturity could be used to set harvest levels for Big Crooked Lake, Wisconsin, because yearly changes in age at maturity reflected yearly changes in walleye population density. To use my model for age at maturity as a predictor of population density in other lakes, the relationship between population density and age at maturity would need to be verified. Population density could be estimated by mark-recapture or another method, and age at maturity could be estimated from samples of gonads and ages obtained during creel or fishery surveys. Inverse prediction (Zar 1999) could then be used to estimate population density from age at maturity with as much precision as population density can be estimated from mark-recapture surveys, as I found. Harvest regulations could then be adjusted to achieve the desired population density. Age at maturity could also be used as an indicator of exploitation stress. If age at maturity for a population decreased, the harvest rate could be lessened to reduce exploitation stress on the population. In contrast to age at $50 \%$ maturity, fecundity is a poor indicator of density, so should not be used to index exploitation stress or to predict density without further study over a broader range of walleye population density.

My findings suggest that walleye populations could be sustained in northern Wisconsin lakes even if total annual exploitation rates of walleye fisheries were increased to $47 \%$ for unregulated angling fisheries, $60 \%$ for angling fisheries with a 15 in minimum length limit, and $60 \%$ for spearing fisheries. However, before implementing an increased annual exploitation rate, my modeling results should be evaluated experimentally. For example, to evaluate the sustainability of walleye populations in lakes that are subjected to spearing fisheries and angling fisheries with a 15-in minimum length limit, three sets 
of lakes could be randomly selected for management under exploitation rates of $35 \%$ (current policy), 60\% (higher sustainable policy), and 75\% (non-sustainable policy). Within each treatment group, spearing quotas and angling creel limits could be set using current methods, though the findings would be clearer if the allocation between spearing and angling was constant for all lakes in the experiment. The number of lakes in each treatment group should be large enough to quantify the natural variation within each group (e.g. 30 lakes per treatment group), but would obviously be limited by available fiscal and human resources.

My simulation model could be strengthened by adding density-dependent growth, to quantify temporal changes in population abundance and related changes in the age at which fish become vulnerable to harvest in each type of fishery. For example, reduced population density would likely lead to faster growth, earlier maturity, and thus, earlier entry to harvest by spearing. To account for such density-dependent changes in growth and selectivity, a Von Bertalanffy length-age sub-model could be added to the simulation model that describes the mean length of fish in each age class $\left(L_{t}=L_{\infty}\left(1-e^{-K\left(t-t_{0}\right)}\right)\right)$. Next, to account for density-dependent changes in population growth rate, parameters of the length-age sub-model could be related to simulated population densities so that the growth rate $(K)$ is directly related to population density and the asymptotic size $\left(L_{\infty}\right)$ is inversely related to population density. Last, to convert changes in growth to changes in fishery selectivity, the mean size of fish in each age class could be related to parameters of the selectivity sub-model $\left(j_{50}\right.$ and $\left.j_{95}\right)$ to change the shape of the selectivity curve with changes in growth (i.e. selectivity shifts to younger age at entry when growth increases). 


\section{REFERENCES}

Baccante, D. A., and D. M. Reid. 1988. Fecundity changes in two exploited walleye populations. North American Journal of Fisheries Management 8: 199-209.

Bagenal, T. B. 1969. The relationship between food supply and fecundity in brown trout Salmo trutta L. Journal of Fish Biology 1: 167-182.

Beard, T. D. Jr., S. P. Cox, and S. R. Carpenter. 2003a. Impacts of daily bag limit reductions on angler effort in Wisconsin walleye lakes. North American Journal of Fisheries Management 23: 1283-1293.

Beard, T. D. Jr., P. W. Rasmussen, S. Cox, and S. R. Carpenter. 2003b. Evaluation of a management system for a mixed walleye spearing and angling fishery in northern Wisconsin. North American Journal of Fisheries Management 23: 481-491.

Becker, G. C. 1983. Fishes of Wisconsin. University of Wisconsin Press, Madison, Wisconsin.

BIA (U. S. Department of the Internal Bureau of Indian Affairs). 1991. Casting light upon the waters: A joint fishery assessment of the Wisconsin Ceded Territory. Fred Meyer, editor. U. S. Department of the Interior Bureau of Indian Affairs, Minneapolis, Minnesota.

BIA (U. S. Department of the Internal Bureau of Indian Affairs). 2003. Casting light upon the waters: A joint fishery assessment of the Wisconsin Ceded Territory. U. S. Department of the Interior Bureau of Indian Affairs, Minneapolis, Minnesota. 
Bowen, S. H., D. J. D’Angelo, S. H. Arnold, M. J. Keniry, and R. J. Albrecht. 1991. Density-dependent maturation, growth, and female dominance in Lake Superior lake herring (Coregonus artedi). Canadian Journal of Fisheries and Aquatic Sciences 48: 569-576.

Brodziak, J. 2002. In search of optimal harvest rates for west coast groundfish. North American Journal of Fisheries Management 22: 258-271.

Bulak, J. S., D. S. Wethey, and M.G. White III. 1995. Evaluation of management options for a reproducing striped bass population in the Santee-Cooper system, South Carolina. North American Journal of Fisheries Management 15: 84-94.

Campana, S. E., W. Joyce, L. Marks, L. J. Natanson, N. E. Kohler, C. F. Jensen, J. J. Mello, H. L. Pratt, Jr., and S. Myklevoll. 2002. Population dynamics of the porbeagle in the northwest Atlantic Ocean. North American Journal of Fisheries Management 22: 106-121.

Carlson, J. K., and I. E. Baremore. 2003. Changes in biological parameters of Atlantic sharpnose shark Rhizoprionodon terraenovae in the Gulf of Mexico: evidence for density-dependent growth and maturity? Marine and Freshwater Research 54: $227-234$.

Colby, P. J., and S. J. Nepszy. 1981. Variation among stocks of walleye (Stizostedion vitreum vitreum): management implications. Canadian Journal of Fisheries and Aquatic Sciences 38: 1814-1831. 
Cross, P. C. and S. R. Beissinger. 2001. Using logistic regression t o analyze the sensitivity of PVA models: a comparison of methods based on African wild dog models. Conservation Biology 15: 1335-1346.

Devries, D. R., and R. V. Frie. 1996. Determination of Age and Growth. Pages 483512 in B. R. Murphy and D. W. Willis, editors. Fisheries Techniques, $2^{\text {nd }}$ edition. American Fisheries Society, Bethesda, Maryland.

Diana, J. S. 1983. Growth, maturation, and production of northern pike in three Michigan lakes. Transactions of the American Fisheries Society 112: 38-46.

Dulvy, N. K., J. R. Ellis, N. B. Goodwin, A. Grant, J. D. Reynolds, and S. Jennings. 2004. Methods of assessing extinction risk in marine fishes. Fish and Fisheries 5: $255-276$.

Ellner, S. P. and J. Fieberg. 2003. Using PVA for management despite uncertainty: effects of habitat, hatcheries, and harvest on salmon. Ecology 84: 1359-1369.

Essington, T. E. 2003. Development and sensitivity analysis of bioenergetics models for skipjack tuna and albacore: a comparison of alternative life histories. Transactions of the American Fisheries Society 132: 759-770.

Fayram, A. H. 2003. A comparison of regulatory and voluntary release of muskellunge and walleyes in northern Wisconsin. North American Journal of Fisheries Management 23: 619-624.

Fox, M. G., and D. D. Flowers. 1990. Effect of fish density on growth, survival, and food consumption by juvenile walleyes in rearing ponds. Transactions of the American Fisheries Society 119: 112-121. 
Frisk, M. G., T. J. Miller, and M. J. Fogarty. 2002. The population dynamics of little skate Leucoraja erinacea, winter skate Leucoraja ocellata, and barndoor skate Dipturus laevis: predicting exploitation limits using matrix analyses. ICES Journal of Marine Science 59: 576-586.

Haddon, M. 2001. Modeling and quantitative methods in fisheries. Chapman and Hall/CRC, Boca Raton, Florida.

Hakoyama, H., and Y. Iwasa. 2000. Extinction risk of a density-dependent population estimated from a time series of population size. Journal of Theoretical Biology 204: $337-359$.

Hansen, M. J. 1989. A walleye population model for setting harvest quotas. Wisconsin Department of Natural Resources, Fish Management Report 143, Madison.

Hansen, M. J., M. D. Staggs, and M. H. Hoff. 1991. Derivation of safety factors for setting harvest quotas on adult walleyes from past estimates of abundance. Transactions of the American Fisheries Society 120: 620-628.

Hansen, M. J., T. D. Beard, and S. W. Hewett. 2000. Catch rates and catchability of walleyes in angling and spearing fisheries in Northern Wisconsin lakes. North American Journal of Fisheries Management 20: 109-118.

Hansen, M. J., S. P. Newman, and C. J. Edwards. 2004. A reexamination of the relationship between electrofishing catch rate and age- 0 walleye density in northern Wisconsin lakes. North American Journal of Fisheries Management 24: $429-439$. 
Hansen, M. J., T. D. Beard Jr., and S. W. Hewett. 2005. Effect of measurement error on tests of density dependence of catchability for walleyes in northern Wisconsin angling and spearing fisheries. North American Journal of Fisheries Management 25: 1010-1015.

Hayes, D. B., C. P. Ferreri, and W. W. Taylor. 1996. Active fish capture methods. Pages 193-220 in B. R. Murphy and D. W. Willis, editors. Fisheries Techniques, $2^{\text {nd }}$ edition. American Fisheries Society, Bethesda, Maryland.

Healey, M. C. 1978. Fecundity changes in exploited populations of lake whitefish (Coregonus clupeaformis) and lake trout (Salvelinus namaycush). Journal of the Fisheries Research Board of Canada 35: 945-950.

Henderson, B. A., and S. J. Nepszy. 1994. Reproductive tactics of walleye (Stizostedion vitreum) in Lake Erie. Canadian Journal of Fisheries and Aquatic Sciences 51: 986-997.

Henderson, B. A., T. Trivedi, and N. Collins. 2000. Annual cycle of energy allocation to growth and reproduction of yellow perch. Journal of Fish Biology 57: 122-133.

Henderson, B. A., and G. E. Morgan. 2002. Maturation of walleye by age, size, and surplus energy. Journal of Fish Biology 61: 999-1011.

Kempinger, J. J., and R. F. Carline. 1977. Dynamics of the walleye (Stizostedion vitreum vitreum) population in Escanaba Lake, Wisconsin, 1955-72. Journal of the Fisheries Research Board of Canada 34: 1800-1811.

Kempinger, J. J., W. S. Churchill, G. R. Priegel, and L. M. Christenson. 1975. Estimate of abundance, harvest, and exploitation of the fish population in Escanaba Lake, 
Wisconsin, 1946-69. Wisconsin Department of Natural Resources Technical Report No. 84.

Koslow, J. A., J. Bell, P. Virtue, and D. C. Smith. 1995. Fecundity and its variability in orange roughy: effects of population density, condition, egg size, and senescence. Journal of Fish Biology 47: 1063-1080.

Legault, C. M. 2005. Population viability analysis of Atlantic salmon in Maine, USA. Transactions of the American Fisheries Society 134: 549-562.

Maceina, M. J., P. W. Bettoli, S. D. Finely, and V. J. DiCenzo. 1998. Analyses of the sauger fishery with simulated effects of a minimum size limit in the Tennessee River of Alabama. North American Journal of Fisheries Management 18: 66-75.

Marmontel, M., S. R. Humphrey, and T. J. O’Shea. 1997. Population viability analysis of the Florida manatee (Trichechus manatus latirostris), 1976-1991. Conservation Biology 11: 467-481.

McCarthy, M. A., M. A. Burgman, and S. Ferson. 1996. Logistic sensitivity and bounds for extinction risks. Ecological Modelling 86: 297-303.

McClanahan, D. R. 2003. A statewide mail survey to estimate 2000-2001 angler catch, harvest and effort in Wisconsin. Master's thesis. University of Wisconsin, Stevens Point.

Muth, K. M., and B. S. Ickes. 1993. Fecundity of walleyes in western Lake Erie, 1966 and 1990-91. Journal of Great Lakes Research 19: 715-719. 
Muth, K. M., and D. R. Wolfert. 1986. Changes in growth and maturity of walleyes associated with stock rehabilitation in western Lake Erie, 1964-1983. North American Journal of Fisheries Management 6: 168-175.

Myers, R. A. 2002. Recruitment: understanding density-dependence in fish populations. Pages 123-148 in P. B. J. Hart and J. D. Reynolds, editors. Handbook of Fish Biology and Fisheries, Volume 1. Blackwell Publishing, Malden, Maine.

Nate, N. A., M. A. Bozek, M. J. Hansen, and S. W. Hewett. 2000. Variation in walleye abundance with lake size and recruitment source. North American Journal of Fisheries Management 20: 119-126.

Nate, N. A., M. A. Bozek, M. J. Hansen, and S. W. Hewett. 2001. Variation of adult walleye abundance in relation to recruitment and limnological variables in northern Wisconsin lakes. North American Journal of Fisheries Management 21: $441-447$.

Nikolskii, G. V. 1969. Theory of fish population dynamics as the biological background for rational exploitation and management of fishery resources. Oliver and Boyd, LTD. Edinburg, England.

Pimm, S. L., H. L. Jones, and J. Diamond. 1988. On the risk of extinction. The American Naturalist 132: 757-785.

Post, J. R., C. Mushens, A. Paul, and M. Sullivan. 2003. Assessment of alternative harvest regulations for sustaining recreational fisheries: model development and application to bull trout. North American Journal of Fisheries Management 23: 22-34. 
Quinn, T. J., and R. B. Deriso. 1999. Quantitative Fish Dynamics. Oxford University Press, New York.

Ricker, W. E. 1975. Computation and interpretation of biological statistics of fish populations. Fisheries Research Board of Canada Bulletin 191, Ottawa, Ontario.

Ricklefs, R. E. 1983. The economy of nature, $4^{\text {th }}$ edition. W. H. Freeman and Company, New York.

Ryder, R. A. and S. R. Kerr. 1990. Harmonic communities in aquatic ecosystems: a management perspective. Pages 594-623 in W. L. T. van Densen, B. Steinmetz, and R. H. Hughes, editors. Management of Freshwater Fisheries. Proceedings of a symposium organized by the European Inland Fisheries Advisory Commission, Goteborg, Sweden. Wageningen: Pudoc.

Scott, D. P. 1962. Effect of food quantity on fecundity of rainbow trout, Salmo gairdneri. Journal of the Fisheries Research Board of Canada 19: 715-731.

Serns, S. L. 1978. Effects of a minimum size limit on the walleye population of a northern Wisconsin lake. Pages 390-397 in R. L. Kendall, editor. American Fisheries Society Special Publication 11, Bethesda, Maryland.

Serns, S. L. 1982. Walleye fecundity, potential egg deposition, and survival from egg to fall young-of-year in Escanaba Lake, Wisconsin, 1979-1981. North American Journal of Fisheries Management 4: 388-394.

Short, P. 2001. A quantitative assessment of spawning habitat for smallmouth bass (Micropterus dolomieu dolomieu) in north Wisconsin lakes. Master's thesis. University of Wisconsin, Stevens Point. 
Spangler, G. R., N. R. Payne, J. E. Thorpe, J. M. Byrne, H. A. Regier, and W. J. Christie. 1977. Responses of percids to exploitation. Journal of the Fisheries Research Board of Canada 34: 1983-1988.

Staggs, M. D., R. C. Moody, M. J. Hansen, and M. H. Hoff. 1990. Spearing and sport angling for walleye in Wisconsin's ceded territory. Wisconsin Department of Natural Resouces, Bureau of Fisheries Management, Administrative Report 31, Madison.

Systat. 2004. SYSTAT II: Statistics I. Systat Software Incorporated, Richmond, Califonia.

Tracy, C. R., and R. L. George. 1992. On the determinants of extinction. The American Naturalist 139: 102-121.

Trippel, E. A. 1995. Age at maturity as a stress indicator in fisheries. BioScience 45: $759-771$.

United States Department of the Interior, Fish and Wildlife Service (USFWS) and United States Department of Commerce, United States Census Bureau. 2003. 2001 National Survey of Fishing, Hunting, and Wildlife-Associated Recreation. United States Department of the Interior, Fish and Wildlife Service and United States Department of Commerce, United States Census Bureau. Available: http://www.census.gov/prod/2002pubs/FHW01.pdf. (February 2004).

Wolfert, D. R. 1969. Maturity and fecundity of walleyes from the eastern and western basins of Lake Erie. Journal of the Fisheries Research Board of Canada 26: $1877-1888$. 
Zar, J. H. 1999. Biostatistical analysis, $4^{\text {th }}$ edition. Prentice-Hall, Inc., Upper Saddle River, New Jersey. 